\title{
4D-Var assimilation of MIPAS chemical observations: ozone and nitrogen dioxide analyses
}

\author{
Q. Errera ${ }^{1}$, F. Daerden ${ }^{1}$, S. Chabrillat ${ }^{1}$, J. C. Lambert ${ }^{1}$, W. A. Lahoz ${ }^{2}$, S. Viscardy ${ }^{1}$, S. Bonjean ${ }^{1, *}$, and D. Fonteyn ${ }^{1, * *}$ \\ ${ }^{1}$ Insitut d'Aéronomie Spatiale de Belgique, BIRA-IASB, Belgium \\ ${ }^{2}$ Norsk Institutt for Luftforskning, NILU, Norway \\ *now at: Sputnik Web, Belgium \\ ** now at: Belgian Federal Science Office, Belgium
}

Received: 11 January 2008 - Published in Atmos. Chem. Phys. Discuss.: 22 April 2008

Revised: 6 August 2008 - Accepted: 5 September 2008 - Published: 24 October 2008

\begin{abstract}
This paper discusses the global analyses of stratospheric ozone $\left(\mathrm{O}_{3}\right)$ and nitrogen dioxide $\left(\mathrm{NO}_{2}\right)$ obtained by the Belgian Assimilation System for Chemical Observations from Envisat (BASCOE). Based on a chemistry transport model (CTM) and the 4-dimensional variational (4DVar) method, BASCOE has assimilated chemical observations of $\mathrm{O}_{3}, \mathrm{NO}_{2}, \mathrm{HNO}_{3}, \mathrm{~N}_{2} \mathrm{O}, \mathrm{CH}_{4}$ and $\mathrm{H}_{2} \mathrm{O}$, made between July 2002 and March 2004 by the Michelson Interferometer for Passive Atmospheric Sounding (MIPAS) onboard the European Space Agency (ESA) Environment Satellite (ENVISAT). This corresponds to the entire period during which MIPAS was operating at its nominal resolution.

Our analyses are evaluated against assimilated MIPAS data and independent HALOE (HALogen Occultation Experiment) and POAM-III (Polar Ozone and Aerosol Measurement) satellite data. A good agreement is generally found between the analyses and these datasets, in both cases within the estimated error bars of the observations. The benefit of data assimilation is also evaluated by comparing a BASCOE free model run with MIPAS observations. For $\mathrm{O}_{3}$, the gain from the assimilation is significant during ozone hole conditions, and in the lower stratosphere. Elsewhere, the assimilation does not provide significant improvement. For $\mathrm{NO}_{2}$, the gain from the assimilation is realized through most of the stratosphere. Using the BASCOE analyses, we estimate the differences between MIPAS data and independent data from HALOE and POAM-III, and find results close to those obtained by classical validation methods involving only direct measurement-to-measurement comparisons. Our results extend and reinforce previous MIPAS data validation
\end{abstract}

Correspondence to: Q. Errera (quentin.errera@aeronomie.be) efforts by taking into account a much larger variety of atmospheric states and measurement conditions.

This study discusses possible further developments of the BASCOE data assimilation system; these concern the horizontal resolution, a better filtering of $\mathrm{NO}_{2}$ observations, and the photolysis calculation near the lid of the model. The ozone analyses are part of the PROMOTE project and are publicly available via the BASCOE website (www.bascoe. oma.be/promote).

\section{Introduction}

Data assimilation is a set of well-known methods that are used to map observations onto a regular grid using the laws of the atmosphere (or other system of interest) embodied in a numerical model. In principle, the resulting "analyses" provide the best estimate of the state of the atmosphere. In numerical weather prediction (NWP), these analyses are used to provide weather forecasts. On the other hand, assimilation systems based on chemical transport models (CTMs) or photochemical box model have broader goals (see Lahoz et al., 2007, Sect. 4): (i) derive information on unobserved species; (ii) test chemical theories; (iii) design constituent measurement strategies; (iv) provide analyses of tropospheric pollution; (v) support the evaluation of satellite instruments; (vi) monitor stratospheric ozone and other constituents; and (vii) forecast stratospheric ozone. More recently, within the GMES Service Element PROMOTE, ESA established a service to provide long term record of 3D ozone fields in order to support SPARC (Stratospheric Process and their Role in Climate) in their Chemistry Climate Model Validation (CCMVal) (Erbertseder et al., 2007).

Published by Copernicus Publications on behalf of the European Geosciences Union. 
The Michelson Interferometer for Passive Atmospheric Sounding (MIPAS) instrument on board ESA's ENVISAT satellite measures the Earth limb emission infrared spectra, from which ESA operational level-1-to-2 processors retrieve the vertical distribution of several key stratospheric species: ozone $\left(\mathrm{O}_{3}\right)$, nitric acid $\left(\mathrm{HNO}_{3}\right)$, nitrogen dioxide $\left(\mathrm{NO}_{2}\right)$, nitrous oxide $\left(\mathrm{N}_{2} \mathrm{O}\right)$, water vapour $\left(\mathrm{H}_{2} \mathrm{O}\right)$, and methane $\left(\mathrm{CH}_{4}\right)$. Several operational centres and research institutes have assimilated MIPAS $\mathrm{O}_{3}$ data successfully using systems based on various model types (CTMs, or general circulation models, GCMs) and various assimilation methods (sequential and variational, e.g., Dethof, 2003; Wargan et al., 2005; Geer et al., 2006; Juckes, 2007). In particular, Baier et al. (2005) assimilated all the six operational MIPAS constituents. Nevertheless, the above-mentioned studies addressed only a few months of MIPAS data, making it difficult to obtain robust statistics valid for a complete annual cycle of atmospheric states and measurement conditions. In this paper, for the first time, an assimilation of the entire MIPAS level-2 data record available at nominal resolution has been done. This record includes the vertical profiles of the six retrieved chemical species from July 2002 to March 2004 (i.e. 21 months). The assimilation has been performed by the BASCOE (Belgian Assimilation System of Chemical Observations from ENVISAT) 4D-Var data assimilation system. BASCOE is based on a 3D CTM driven by meteorological analyses of winds and temperature provided by the European Centre for Medium-range Weather Forecasts (ECMWF). Near real time assimilation of MIPAS level 2 data and short-term chemical forecasts have also been made with an earlier version of BASCOE within the framework of ENVISAT cal/val activities(Fonteyn et al., 2002, 2004, see also www.bascoe.oma.be/archives).

This paper presents and discusses the assimilation of MIPAS level-2 data retrieved with ESA's off-line Instrument Processing Facility (IPF) versions 4.61 and 4.62. We focus on analyses of $\mathrm{O}_{3}$ and $\mathrm{NO}_{2}$. Monitoring of independent observations from HALOE (HALogen Occultation Experiment) and POAM-III (Polar Ozone and Aerosol Measurement) is also achieved during the assimilation procedure; this has not been done in previous MIPAS assimilation studies. The monitoring procedure uses the same model-toobservation operator as the assimilation procedure, i.e. the model values are interpolated to the locations of the observations available around the model time step (see Sect. 3). This allows optimal comparison of the BASCOE analyses against HALOE and POAM-III data since we do not use analyses given at standard output times (e.g. every $6 \mathrm{~h}$ ). Based on our analyses, we estimate the bias between MIPAS and independent data and our results are compared to those obtained by classical validation methods limited to direct measurementto-measurement comparisons. HALOE, POAM-III and MIPAS data have also been monitored with a six-month free model run, initialized with analysed data. Comparison between the analyses and the free model run allows us to dis- cuss the added value provided by data assimilation. What is new in this paper is: (1) the extended assimilation period (especially for $\mathrm{NO}_{2}$ ) which allows us to derive robust statistics valid for the widest range of atmospheric states and measurement conditions; (2) the monitoring procedure, which allows us to evaluate the datasets in an optimal manner; and (3) the use of BASCOE analyses to derive differences between MIPAS and independent data from HALOE and POAM-III, even in the absence of direct collocation of the air masses measured by the different satellites.

The paper is organized as follows. Sections two, three and four describe, respectively, the BASCOE system, the data used in this study and the set-up of the assimilation experiments. Sections five and six discuss, respectively, the $\mathrm{O}_{3}$ and $\mathrm{NO}_{2}$ analyses. Conclusions and possible further developments are given in Sect. 7.

\section{System description}

The Belgian Assimilation System of Chemical Observations from ENVISAT (BASCOE) is a 4-dimensional variational (4D-Var) system descended from that described in Errera and Fonteyn (2001). Model studies of the 2003 Antarctic winter using the BASCOE CTM coupled with a Polar Stratospheric Cloud (PSC) microphysical scheme can be found in Daerden et al. (2007). Fonteyn et al. (2002, 2004) used a version of BASCOE that includes the microphysical scheme for near real time assimilation of MIPAS (see also www.bascoe.oma.be/archives). A version of BASCOE where the microphysical scheme was replaced by a parameterization has been used in the framework of the ASSET ozone intercomparions (Geer et al., 2006) and of the validation of MIPAS $\mathrm{HNO}_{3}$ and $\mathrm{N}_{2} \mathrm{O}$ (Vigouroux et al., 2007). In this paper, we focus on the version including the parameterization of the microphysics.

\subsection{The 3D-CTM}

All chemical species are advected using the Flux Form SemiLagrangian scheme (Lin and Rood, 1996) with a time step of 30 min; The CTM is driven by ECMWF operational analyses of winds and temperatures, and uses a subset of 37 of the 60 ECMWF model levels, from the surface to $0.1 \mathrm{hPa}$, on a $5^{\circ}$ longitude by $3.75^{\circ}$ latitude grid. The model grid type is Arakawa C (Kalnay, 2003).

The model includes 57 chemical species with a full description of stratospheric chemistry. The species interact through 143 gas-phase reactions, 48 photolysis reactions and 9 heterogeneous reactions. The chemical system of differential equations is built using the Kinetic PreProcessor (Damian et al., 2002) and is integrated with a third-order Rosenbrock solver (Hairer and Wanner, 1996). The reaction rates and cross-sections are taken from the JPL compilation Evaluation 14 (Sander et al., 2003). 
The Surface Area Density (SAD) of sulfate aerosols is prescribed as a function of pressure and latitude, using the climatological distribution described by Daerden et al. (2007). While Daerden et al. (2007) couple a PSC microphysical scheme to the CTM, here we use a parameterization that sets the surface area density of PSCs and calculates the loss of $\mathrm{HNO}_{3}$ and $\mathrm{H}_{2} \mathrm{O}$ by PSC sedimentation as a function of temperature. Ice PSCs are presumed to exist in the winter/spring Polar Regions at any grid point where the temperature is colder than $186 \mathrm{~K}$, and Nitric Acid Tri-hydrate (NAT) PSCs at any grid point where the temperature is colder than $194 \mathrm{~K}$. The surface area density is set to $10^{-6} \mathrm{~cm}^{-2} / \mathrm{cm}^{-3}$ for ice PSCs and $10^{-7} \mathrm{~cm}^{-2} / \mathrm{cm}^{-3}$ for NAT PSCs. The sedimentation of PSC particles causes denitrification and dehydration. This process is also approximated in a very simple way, by an exponential decay of $\mathrm{HNO}_{3}$ with a characteristic time-scale of 100 days for gridpoints where NAT particles are supposed to exist, and an exponential decay of $\mathrm{HNO}_{3}$ and $\mathrm{H}_{2} \mathrm{O}$ with a characteristic time-scale of 9 days for gridpoints where ice particles are supposed to exist (Solomon and Brasseur, 1997).

All species simply have null a flux at upper and lower boundary conditions. While the model extends down to the surface, it does not include any tropospheric process and is not expected to produce a realistic chemical composition below the tropopause.

\subsection{The 4D-Var system}

Data assimilation is done using 4D-Var (Talagrand and Courtier, 1987). This method optimizes the model initial conditions to reproduce a set of observations over a time window. This is done by minimizing the following objective function, $J(\mathbf{x})$ (also denoted cost function) (Talagrand and Courtier, 1987) using the standard notation of Ide et al. (1997):

$$
\begin{aligned}
J(\mathbf{x})= & \frac{1}{2}\left[\mathbf{x}\left(t_{0}\right)-\mathbf{x}^{\mathrm{b}}\left(t_{0}\right)\right]^{T} \mathbf{B}_{0}^{-1}\left[\mathbf{x}\left(t_{0}\right)-\mathbf{x}^{\mathrm{b}}\left(t_{0}\right)\right]+ \\
& \frac{1}{2} \sum_{i=0}^{N}\left(\mathbf{y}^{\mathrm{o}}\left(t_{i}\right)-H\left(\mathbf{x}\left(t_{i}\right)\right]\right)^{T} \mathbf{R}_{i}^{-1}\left(\mathbf{y}^{\mathrm{o}}\left(t_{i}\right)-H\left(\mathbf{x}\left(t_{i}\right)\right]\right)
\end{aligned}
$$

given the model evolution equation

$\mathbf{x}\left(t_{i}\right)=M_{i-1}\left[\mathbf{x}\left(t_{i}-1\right)\right]$

where $\mathbf{x}\left(t_{i}\right)$ represents the model state vector at time $t_{i}, \mathbf{x}^{\mathrm{b}}\left(t_{0}\right)$ is the first guess and $\mathbf{B}_{0}$ is the background error covariance matrix of $\mathbf{x}^{\mathrm{b}}\left(t_{0}\right)$. Vectors $\mathbf{y}^{\mathrm{o}}\left(t_{i}\right)$ and matrix $\mathbf{R}_{i}$ are, respectively, the observation state vector and the error covariance matrix associated with the observations at time $t_{i}$. The observation operator $H$ maps the model state into the observation space and $M$ is the model operator that calculates the time evolution of the model state. Minimization of Eq. (1) requires the knowledge of the gradient of $J$. This is done using the adjoint of the forward (or direct) model. The minimization of the objective function uses the quasi-Newton algorithm M1QN3 (Gilbert and Lemarechal, 1989) and the system is preconditioned (Bouttier and Courtier, 2002).

Three processes in the BASCOE model affect chemical concentrations: advection, chemistry and the PSC parameterization. The adjoint code of these processes is required for implementation of 4D-Var. Although the number of species and reactions, and the advection scheme have changed since Errera and Fonteyn (2001), their adjoint has been built following the same procedure. The adjoint of the PSC parameterization has been built by hand. Note that several approaches can be used to build chemistry adjoints (see Sandu et al., 2003, for a review). In one approach, the adjoint of the chemistry is the adjoint of the chemical system of equations and the backward integration in time is done with the same integrator as for the forward case, as is done in Errera and Fonteyn (2001). Sandu et al. (2003) discuss what they term the continuous and discrete approaches to the calculation of chemistry adjoints. In this context, the approach of Errera and Fonteyn (2001) falls in the continuous category. If one wishes to avoid this approximation, which means using the discrete approach, the adjoint of the integrator for the backward case should also be built.

Because the set-up of Errera and Fonteyn (2001) gave good results, it was used in the formulation of the BASCOE adjoint. However, there are four time periods where the minimization is not attained, i.e., the system is not able to reduce $J$ during the iteration process. These periods are: (1) 6 days in September 2002, during the Antarctic vortex split; (2) 6 days during mid February 2002; (3) 15 days during March 2003; and (4) 17 days between mid September and the beginning of October 2003.

The reasons for this failure are still under investigation. However, there are clues that point to possible causes. For example, the problem occurs with data located above $3 \mathrm{hPa}$ and in the Polar Regions. We do not think that the source of this problem is due to the observations because: (1) data corresponding to days without minimization are not so different than data for days where the minimization is achieved; and (2) a data filter is already implemented to reject outliers (see Sect. 4). It is more likely that the fast dynamical changes that can occur in the high Polar Stratosphere are not compatible with the approximations used to calculate the adjoint of the chemistry. As a result, small errors arising from these approximations are amplified by the adjoint of the transport.

In order to provide the most complete dataset of analyses and avoid problematic cases, we choose to filter out all observations for levels above $3 \mathrm{hPa}$ and for latitudes poleward of $\left| \pm 50^{\circ}\right|$ for these days. Note that previous studies based on BASCOE analyses of MIPAS (Geer et al., 2006; Vigouroux et al., 2007) did not filter out these observations for these days. As a result, in these studies, no minimization was obtained during these days and the corresponding analyses must be considered as an output of the BASCOE CTM. 


\section{The observations}

Three satellite datasets are used in this study: MIPAS data are assimilated by the BASCOE system to constrain its CTM outputs, while HALOE and POAM-III data are monitored by the system and used for a posteriori evaluation of the BAS$\mathrm{COE}$ analyses. Assimilated data are volume mixing ratio at the location of the tangent point and the observation operator interpolates linearly the model values at the eight grid points to the surrounding tangent point of any available observation at $\pm 15 \mathrm{~min}$ of the model time step. In the monitoring procedure, the BASCOE observation operator is used only to map the analyses at HALOE and POAM-III locations. Finally, BASCOE analyses interpolated at observation locations (assimilated or monitored) are saved in a file for a posteriori statistics.

Using the monitoring procedure, the maximum time mismatch between measurement and model values is $15 \mathrm{~min}$. This is an important detail, especially for $\mathrm{NO}_{2}$, given the diurnal cycle of this species and its rapid variation at scales of minutes during twilight. Note that, unlike in NWP centers, the monitoring procedure is not commonly used by the assimilation system of research institutes.

\subsection{MIPAS}

The ENVISAT MIPAS instrument measures nighttime and daytime Earth limb emission high-resolution spectra with a Michelson interferometer (Fischer et al., 2008). The vertical distribution of numerous atmospheric trace gas can be retrieved from MIPAS spectra using Fourier Transform spectroscopy. Here, the six chemical species retrieved operationally by ESA's off-line processor are assimilated: $\mathrm{O}_{3}$, $\mathrm{HNO}_{3}, \mathrm{H}_{2} \mathrm{O}, \mathrm{NO}_{2}, \mathrm{~N}_{2} \mathrm{O}$ and $\mathrm{CH}_{4}$. All species are assimilated together without any distinction of day or night data. Usually there are around 1000 MIPAS profiles per day. Twenty-one months of data have been assimilated (18 July 2002-26 March 2004). We combine off-line versions 4.61 and 4.62 to increase the period of MIPAS observations: for example, after 7 December 2003, only v4.62 data are available. However, each daily dataset comes from a single version. Both ozone (v4.61 and v4.62, Cortesi et al., 2007) and nitrogen dioxide (v4.61, Wetzel et al., 2007) have been validated for scientific applications. Between 1 to $50 \mathrm{hPa}$, the ozone bias with respect to correlative data is lower than $10 \%$; it increases to $25 \%$ at $100 \mathrm{hPa}$. At levels above $1 \mathrm{hPa}$, the number of correlative data are too small to derive quantitative conclusions (Cortesi et al., 2007). In the lower and middle stratosphere (below $1 \mathrm{hPa}$ ), the accuracy and precision of MIPAS $\mathrm{NO}_{2}$ are $10-20 \%$ and 5-15\%, respectively (Wetzel et al., 2007).

\subsection{HALOE}

Operating aboard NASA's Upper Atmosphere Research Satellite (UARS) from 1991 through 2005, HALOE (Russell III et al., 1993) used solar occultation to measure atmospheric constituent profiles of $\mathrm{O}_{3}, \mathrm{NO}, \mathrm{NO}_{2}, \mathrm{HCl}, \mathrm{CH}_{4}$, $\mathrm{HF}$ and aerosol extinction. About 15 sunset and sunrise occultations (30 altogether) were performed every day. The $56^{\circ}$ inclination of the UARS orbit generated a small daily precession of the latitude of the sunrises and sunsets, yielding global coverage from $50^{\circ} \mathrm{S}-80^{\circ} \mathrm{N}$ to $50^{\circ} \mathrm{N}-80^{\circ} \mathrm{S}$ in about one month. Version 19 of HALOE, the latest version available publicly, is used here to validate the BASCOE analyses. Intercomparison of ozone (as delivered in the earlier version 17) with correlative data (acquired by ozonesonde, lidar, balloon-borne remote sensing, rocketsondes and other satellites) shows good agreement, usually within the estimated measurement errors, between 0.03 to $100 \mathrm{hPa}$ (Brühl et al., 1996). Between 1 and $30 \mathrm{hPa}$, the agreement is around $5 \%$. Comparison of version 19 shows agreement of 5\% against, respectively, SAGE-II v6.1 between 20 and $50 \mathrm{~km}$ (50 and $0.5 \mathrm{hPa}$ ) (Nazaryan et al., 2005), ozonesondes in the lower stratosphere (Bhatt et al., 1999) and POAM-III between 13 and $60 \mathrm{~km}(150$ and $0.1 \mathrm{hPa}$ ) (Randall et al., 2003). The HALOE NO and $\mathrm{NO}_{2}$ measurements have been validated using satellite, balloon and ground based measurements (Gordley et al., 1996, for version 17). In the middle stratosphere, the $\mathrm{NO}_{2}$ measurements show mean differences with independent data of about 10 to $15 \%$. NO differences in the middle stratosphere are similar, but sometimes show a negative bias (as much as 35\%) between 30 and $60 \mathrm{~km}$ (10 to $0.1 \mathrm{hPa}$ ) with some correlative measurements. In this study, analyses of $\mathrm{NO}_{\mathrm{x}}\left(\mathrm{NO}+\mathrm{NO}_{2}\right)$ are compared with HALOE $\mathrm{NO}_{\mathrm{x}}$. This is done to minimize the error of interpolation, which could be non negligible, at the terminator due to the maximum time shift of 15 min between BASCOE analyses and observations (see above).

\subsection{POAM-III}

Owing to the polar orbit of the SPOT-4 platform (98. $6^{\circ}$ inclination), POAM-III, which is also a solar occultation instrument, measures the vertical distribution of the chemical stratospheric constituents $\mathrm{O}_{3}, \mathrm{NO}_{2}, \mathrm{H}_{2} \mathrm{O}$ and aerosol extinction in the Polar Regions (Lucke et al., 1999). Here we use the latest POAM-III version 4 data. Since the SPOT-4 orbit has helio-synchronous precession, the latitude of occultations varies only slightly with the season, and it remains in the Polar Regions, in the $63^{\circ} \mathrm{S}-88^{\circ} \mathrm{S}$ and $55^{\circ} \mathrm{N}-$ $71^{\circ} \mathrm{N}$ ranges. In its original configuration (Lumpe et al., 2002), POAM-III recorded 14 sunrise and 14 sunset occultations per day, corresponding to the Northern Hemisphere $(\mathrm{NH})$ and Southern Hemisphere (SH), respectively. However, after about one year, POAM-III developed a mechanical problem with the azimuthal motion (Karl Hoppel, personnal 
communication). In order to reduce this motion, $\mathrm{SH}$ and $\mathrm{NH}$ measurements were made on alternate days, which decrease the nominal number of daily occultations by a factor of 2 . The terms "sunset" and "sunrise" used in Lumpe et al. (2002) refer to spacecraft geometry, not to the local ground time. Sunrise is when the spacecraft goes from dark to light, and sunset is when the opposite occurs. For the POAM-III orbit, $\mathrm{NH}$ measurements (spacecraft sunrise) always occur at the local sunset time. In the SH, the local time of the POAMIII measurements switch from sunset to sunrise around the spring Equinox in the beginning of April, and switch from sunrise to sunset around the autumn Equinox in the beginning of September. This configuration can affect intercomparison against BASCOE, especially for $\mathrm{NO}_{2}$ (see Sect. 6 and Randall et al., 2007). In the following, POAM-III sunset and sunrise will refer to the local ground time, not to the spacecraft time.

On average, POAM-III version $4 \mathrm{O}_{3}$ profiles agree within $5 \%$ with respect to correlative data (HALOE version 19, SAGE-II version 6.20 and ozonesondes) from 13 to $60 \mathrm{~km}$ (Randall et al., 2003). Comparison of POAM-III version 4 and HALOE version $19 \mathrm{NO}_{2}$ data shows good agreement, within $6 \%$ from 20 to $33 \mathrm{~km}$ and increasing to $12 \%$ at $40 \mathrm{~km}$ (Randall et al., 2002).

\subsection{Intercomparison method}

As mentioned above, BASCOE outputs are saved at the observation location of the instruments whose data are monitored or assimilated. The BASCOE and observational datasets are intercompared by calculating the bias and standard deviation for selected latitude and pressure bins. Five standard latitude bins are defined using the following six boundaries: $-90^{\circ},-60^{\circ},-30^{\circ}, 30^{\circ}, 60^{\circ}$, and $90^{\circ}$. Pressure layer bins are based on the UARS pressure grid, calculated from the following formula (in $\mathrm{hPa}$ ): $10^{i / 12}, i=-12$, $-10,-8, \ldots 28$. The pressure levels indicating the pressure layers are defined using the same formula with $i=-11,-9$, $-7, \ldots 29$. The lower and upper pressure boundaries are at 0.12 and $261 \mathrm{hPa}$, respectively. Thus, 21 pressure bins are used from the upper stratosphere lower mesosphere (USLM) to the upper troposphere lower stratosphere (UTLS). The bias and standard deviation between analyses and observations are calculated for each latitude/pressure interval. Biases are calculated as the difference Observation minus Analyses. Thus, a positive bias indicates that BASCOE underestimates the observations. Both standard deviation and bias are averaged for the time periods of interest. In general, bias and standard deviation are given in relative units (percent). In this case, they are normalized by the mean of the observations in the time/latitude/pressure interval. Note that, unlike Geer et al. (2006), we do not interpolate the data nor the analyses to a regular grid.

\section{BASCOE set-up}

BASCOE runs are initialized with three dimensional fields of atmospheric constituents on 12 July 2002 calculated by the SLIMCAT CTM (Chipperfield, 1999). BASCOE is run in the free model mode until the first day of MIPAS observations (18 July 2002). For each species, the background error covariance matrix $\mathbf{B}$ is defined as diagonal with a standard deviation set to $20 \%$ of the background volume mixing ratio. The choice of $20 \%$ is empirical and is based on our experience with this chemical data assimilation system. The diagonal set-up of $\mathbf{B}$ implies that both spatial and speciesspecies correlations are neglected. Spatial correlations help to spread the information from the data into the model. They can be neglected in first approximation if the spatial coverage of the assimilated observations and their vertical resolution are comparable to the model resolution. This is the case here, where a maximum of three days of MIPAS observations are necessary to constrain all BASCOE grid points. On the other hand, to the best of our knowledge, multivariate assimilation (i.e. the implementation of species-to-species correlations in the formulation of $\mathbf{B}$ ) has never been done ${ }^{1}$. For species that interact together with a time scale of the order of several days, the correlations are implicitly set up by the chemical coupling present in the model and its adjoint. Multivariate assimilation could be useful to constrain an unobserved tracer (e.g., $\mathrm{N}_{2} \mathrm{O}$ ) by an observed tracer (e.g., $\mathrm{CH}_{4}$ ) using their compact relationship.

Errors in MIPAS observations are basically of two types. The random error is the contribution of the instrument noise in the retrieval while the systematic error is the contribution of all other sources of uncertainties. ESA provides MIPAS observations with only their random error. When this study started, the error budget of MIPAS (including the systematic error) made by the MIPAS team was not available (Raspollini et al., 2006, see also www.atm.ox.ac.uk/group/mipas/err/). If MIPAS data were to be assimilated using only the random error, the weight of the observations in the final analyses would be too high. To avoid this, BASCOE add an error of $8.5 \%$ to the random error for each MIPAS species at each location; this arbitrary value has been tested for a few days of assimilation and found to be satisfactory. It has been kept for the complete period presented in this paper. To a first approximation, for $\mathrm{O}_{3}$ and $\mathrm{NO}_{2}$, the observational error set up in BASCOE is close to the MIPAS total (random plus systematic) errors. Note that we do not include any error of representativeness, e.g., to take into account the error introduced by the spatial interpolation and the time-lag between BASCOE and MIPAS. This error could be significant, especially for species with diurnal cycle like $\mathrm{NO}_{2}$.

In order to prevent outlier data unduly constraining the system, an Optimal Interpolation Quality Check (OIQC; Gauthier et al., 2003) was set-up for the near-real-time

\footnotetext{
${ }^{1}$ An alternative is discussed in Chipperfield et al. (2002)
} 


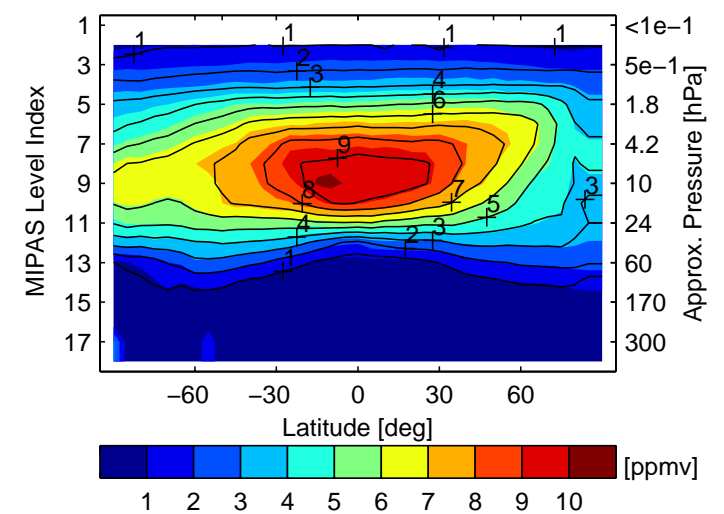

Fig. 1. Zonal mean of $\mathrm{O}_{3}$ (ppmv) from MIPAS (isocontours) and BASCOE (isolines) on 6 October 2003 and averaged on a $5^{\circ}$ latitude grid. The left-hand side vertical axis is the MIPAS vertical level index (1 highest, 17 lowest).

BASCOE assimilation. This set-up has been kept for the assimilation of MIPAS off-line data discussed in this paper. It rejects data when their difference with the background state is greater than three times the background error. We will see later that this filter prevents the assimilation of $\mathrm{NO}_{2}$ produced by Energetic Particles Precipitation (EPP) processes like Solar Proton Events (SPEs). A better filter would involve comparison of MIPAS data with another reference state than the background state. For example, the median value of MIPAS observations taken in similar atmospheric condition (e.g., in the polar vortex) would be a better reference state.

In addition to the assimilation, a free model run of the BASCOE CTM is done to evaluate the benefits of the assimilation. This control run starts on 1 May 2003 and ends on 30 November 2003. It is initialized by the BASCOE analyses on 1 May.

\section{Ozone results}

This section is divided in three subsections. In Subsect. 5.1, BASCOE analyses are compared to MIPAS to check their consistency. Subsection 5.2 validates the BASCOE analyses using independent observations from HALOE and POAMIII. Finally, Subsect. 5.3 uses BASCOE analyses to validate MIPAS against HALOE and POAM-III. The same structure is used in Sect. 6.

\subsection{Consistency of analyses: BASCOE vs. MIPAS}

The consistency between MIPAS ozone data and BASCOE ozone analyses is illustrated in Fig. 1. It shows the ozone zonal mean on 6 October 2003 for MIPAS and the corresponding analyses. The vertical layers are the 17 MIPAS levels and the latitudinal average is done with $5^{\circ}$ resolution. Below the ozone maximum (around MIPAS retrieval level 9) minor differences exist between both datasets. Above this level, BASCOE underestimates the ozone MIPAS data (the isolines do no fit the isocontours), but the differences are not too high.

In order to quantify the consistency between BASCOE and MIPAS, we show in Fig. 2 the bias and standard deviation for three comparisons: (1) MIPAS assimilated data against BASCOE ("stat1"), (2) all MIPAS data (i.e., including data rejected by the quality control filter) against BASCOE ("stat2"), and (3) all MIPAS data against the control run described in Sect. 4 ("stat3"). The statistics are calculated using the method described in Sect. 3.4. They are calculated for the period September-October 2003, five latitude bands and 21 pressure layers. Figure 2 also shows the number of observations used to compute the statistics. For comparison, the MIPAS systematic and random error for ozone (see Sect. 4) is added in the bias and standard deviation plots, respectively.

Comparison between stat 1 and stat 2 tells us how many data have been rejected and, if this number is significant, to which degree assimilated data are representative of the whole dataset. At the poles and above $10 \mathrm{hPa}$, a significant number of observations are rejected but the bias and the standard deviation of the two statistics are similar. This indicates that the data filter is set up correctly for this region. At the tropical tropopause and during the ozone hole at the South Pole, the amount of rejected data is also significant but the statistics are different. This indicates that the data filter is not optimal there. Since the data filter currently uses as reference the background state, there are two ways to improve data filtering in future studies: improve the model or finding a better reference state.

Comparison between stat 2 and the MIPAS errors shows that in most cases, the assimilation succeeds in producing analyses in agreement with MIPAS within its uncertainties. This positive result has three exceptions. Around $0.5 \mathrm{hPa}$, MIPAS is underestimated by BASCOE with a significant bias of around $20 \%$ (see the later discussion on the analyses around the $0.5 \mathrm{hPa}$ level). At the Poles, both the bias and standard deviation are larger than the MIPAS error. Here, increasing the resolution to get a stronger barrier at the vortex edges should allow a decrease in the ozone volume mixing ratio (vmr) and an improvement in the analyses. In the troposphere, BASCOE analyses underestimate significantly the MIPAS observations due to the absence of tropospheric processes in the BASCOE CTM and the degradation of the quality of MIPAS data (Cortesi et al., 2007).

Comparison between stat 2 and stat 3 shows what gain we can expect from the assimilation. Overall, the analyses deliver a smaller bias and a smaller standard deviation than the control run. The regions that most significantly benefit from the assimilation are the lower stratosphere and the Poles. In these regions, there is a gain from the assimilation, even where analyses do not agree with MIPAS within its error. 


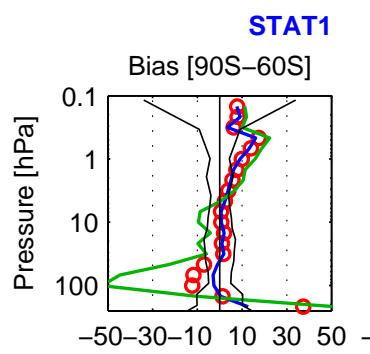

[\%]

Std. Dev. [90S-60S]

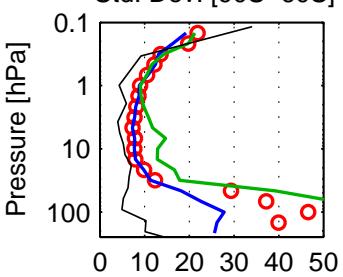

[\%]

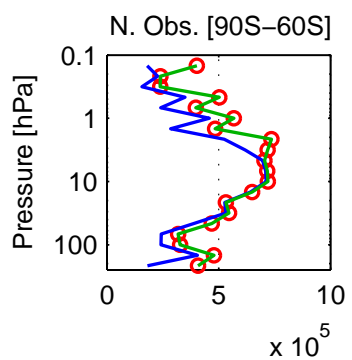

STAT2
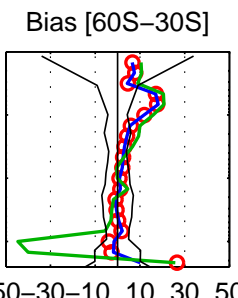

[\%]

Std. Dev. [60S-30S]

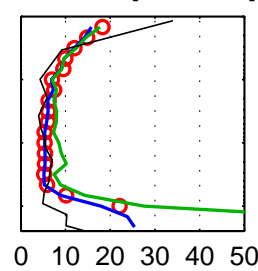

[\%]

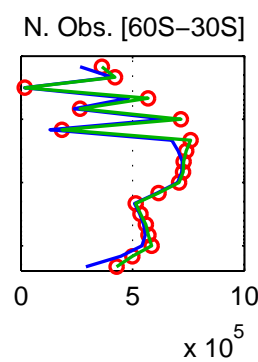

STAT3

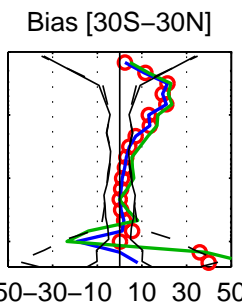

[\%]

Std. Dev. [30S-30N]

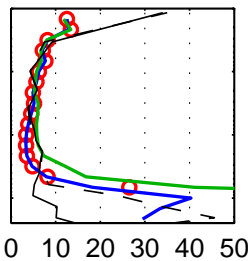

[\%]

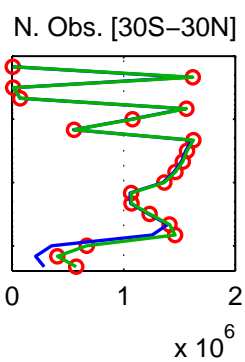

MIPAS ERROR

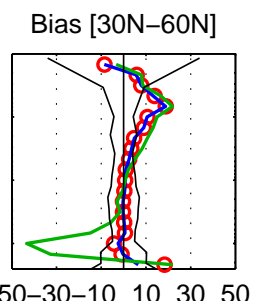

[\%]

Std. Dev. [30N-60N]

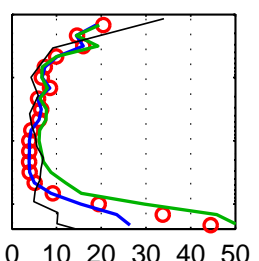

[\%]

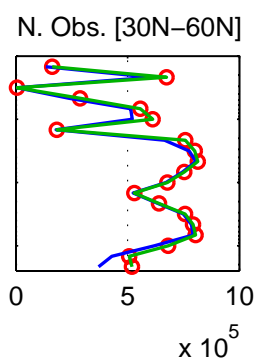

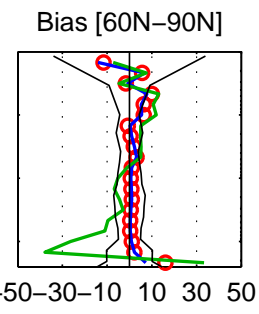

[\%]
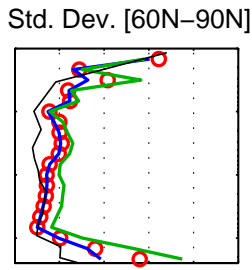

[\%]

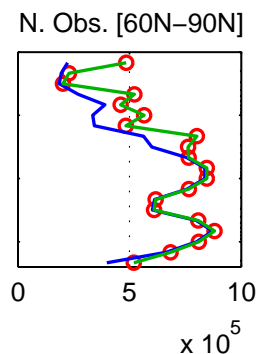

Fig. 2. Comparison between MIPAS $\mathrm{O}_{3}$ and BASCOE for the September-October 2003 period: (1) assimilated MIPAS data vs BASCOE (stat1 - see text, solid blue), (2) all MIPAS data (including those rejected by QC filter) vs BASCOE (stat2 - see text, red circles) and (3) all MIPAS data and the BASCOE control run (stat3 - see text, solid green). Upper row shows the mean differences between MIPAS and BASCOE (the bias) calculated as Mean(MIPAS-BASCOE)/Mean(MIPAS). The middle row shows the standard deviation of the mean differences and the lower row shows the number of observations used per latitude band and pressure level. Zero values in the profiles of number of observations correspond to UARS pressure layers without MIPAS observations. The solid black line in the bias plots is the MIPAS nighttime systematic error (daytime error is similar) and the dashed black line in the bias plots in the region [30 S-30 N] is the MIPAS daytime systematic error at the Equator. In the standard deviation plots, MIPAS random error is shown instead of systematic error. See Sect. 3.4 for details of the intercomparison method.

In order to assess the temporal consistency of the BAS$\mathrm{COE}$ analyses, we plot in Fig. 3 the time series of the bias and the standard deviation of the differences between BASCOE and MIPAS (stat2) for three pressure layers, five latitude bands and the entire twenty-one months of assimilation. Around the ozone maximum, between 8 and $12 \mathrm{hPa}$, the statistics are stable in time except for the standard deviation at the winter Poles (e.g. we observe a maximum of $20 \%$ for the standard deviation in July). For all other latitudes and time periods at levels around the ozone maximum, the bias and standard deviation of the differences are not significant. At higher levels, between 0.6 and $1.8 \mathrm{hPa}$, BASCOE underestimates MIPAS, as discussed above. For levels between 82 and $121 \mathrm{hPa}$, the bias and standard deviation are generally consistent in time except at the Tropics and during the ozone hole period. In general, the statistics show higher variability at the Poles and at the tropical tropopause, two regions that can have a strong dynamical barrier. Increasing the resolution of BASCOE would likely reduce the bias and standard deviation, as discussed by Strahan and Polansky (2006).

We now consider the underestimation of MIPAS data by BASCOE at levels around $0.5 \mathrm{hPa}$. Figure 4 shows the bias between MIPAS and BASCOE (stat2), and MIPAS and the control run (stat3) over the tropical latitudes. For this plot, we show the statistics for MIPAS nighttime and daytime data separately. The main differences between the daytime and nighttime statistics occur above $1 \mathrm{hPa}$, where there is significant bias between BASCOE and MIPAS. The control run shows the same behaviour, with a bias slightly higher than that for the analyses. This suggests the bias comes from the model, unlike stated in Errera et al. (2007) who mentioned a potential problem in the MIPAS observations. We suggest that this low bias is related to photolysis calculations in BAS$\mathrm{COE}$, a bias that cannot be reduced by the assimilation. 

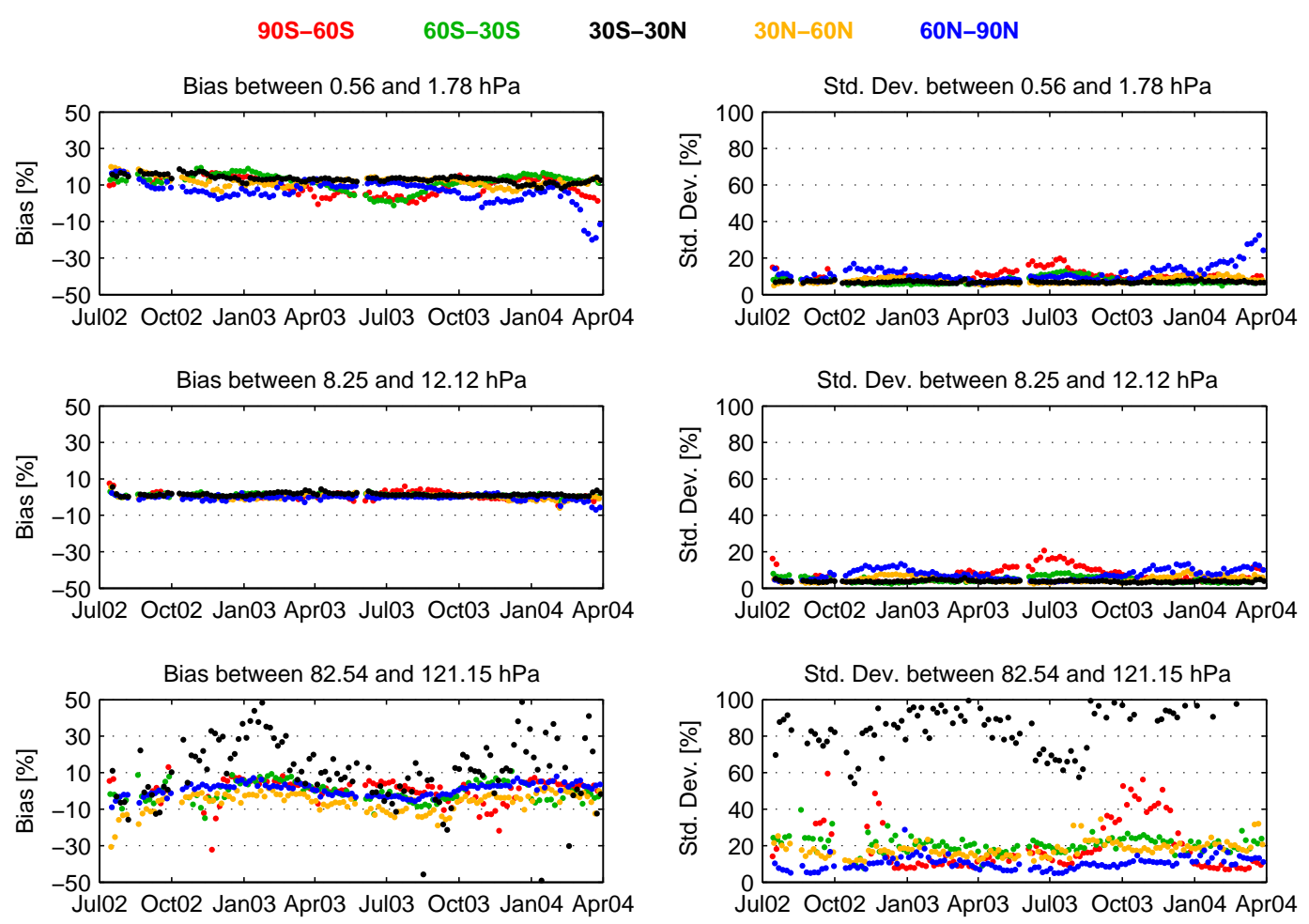

Fig. 3. Time series of bias (left column) and standard deviation (right column) between all MIPAS $\mathrm{O}_{3}$ data and BASCOE (stat 2 - see text) for the five latitude bands (see text), three pressure layers (top: $0.56-1.78 \mathrm{hPa}$; middle: $8.25-12.12 \mathrm{hPa}$; bottom: $82.54-121.15 \mathrm{hPa}$ ) and the whole assimilation period July 2002-March 2004. Each dot represents a five day average.

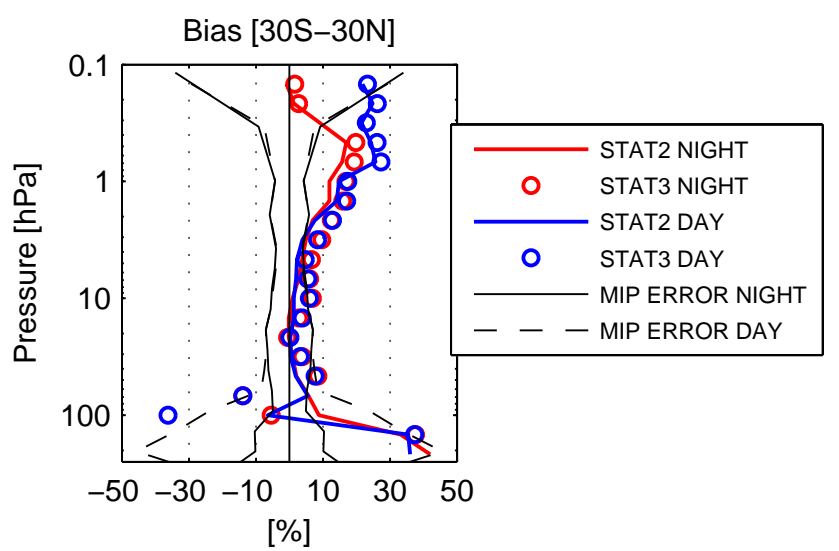

Fig. 4. Comparison between MIPAS $\mathrm{O}_{3}$ and BASCOE (stat 2 - see text) and between MIPAS $\mathrm{O}_{3}$ and the control run (stat3 - see text) considering separately daytime and nighttime MIPAS observations, for September-October 2003 over the tropical latitudes. The full dark and dashed lines represent the MIPAS systematic error for nighttime and daytime observations, respectively.
The $0.5 \mathrm{hPa}$ level is near to the third pressure layer of BASCOE, i.e., close to the model lid. The photolysis calculations at each model layer depend on the overhead ozone column. Above $0.1 \mathrm{hPa}$, this value is not known and has been set to 0.02 Dobson Units. Improving the photolysis calculations at these levels would require a parameterization of the ozone column above the model lid, or the addition of extra model layers above $0.1 \mathrm{hPa}$. These improvements are planned in future versions of the model.

5.2 Validation of analyses: BASCOE vs. independent observations

To validate the analyses, we compare them against independent observations from HALOE and POAM-III. Figure 5 shows the bias and standard deviation of the differences between BASCOE and, respectively, independent observations from HALOE and POAM-III, for the period SeptemberOctober 2003. This period is representative of the 21 months considered here, except for the lower South Pole stratosphere. In the middle stratosphere, between 2 and $50 \mathrm{hPa}$, and outside ozone hole conditions, the agreement between BASCOE and independent data from HALOE and POAMIII is generally within HALOE and POAM-III uncertainties (see Sects. 3.2 and 3.3), i.e., bias and standard deviation are 


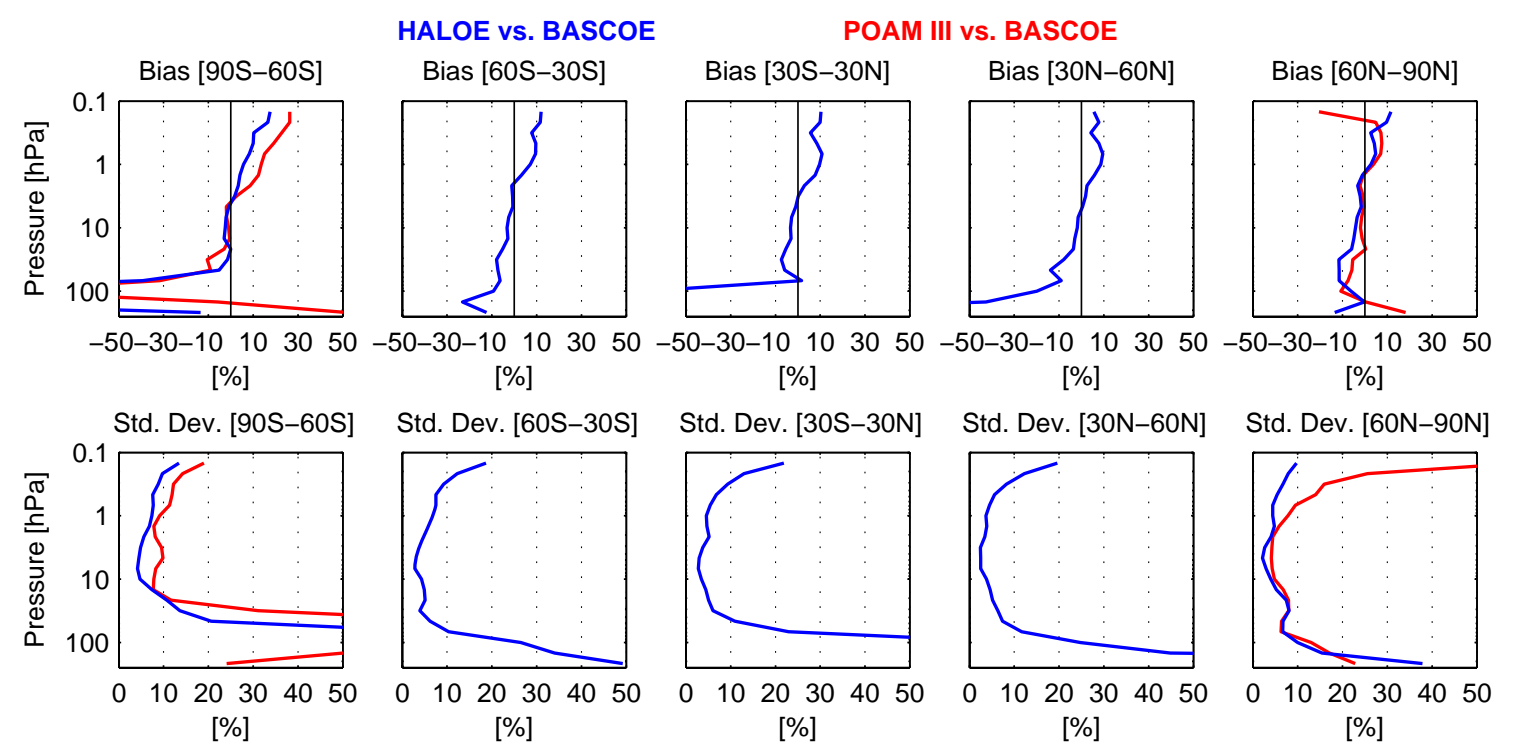

Fig. 5. Comparison between BASCOE $\mathrm{O}_{3}$ analyses and independent observations HALOE and POAM-III for the period September-October 2003 and five latitude bands. Blue: HALOE vs. BASCOE, red: POAM-III vs. BASCOE. A positive value for the bias indicates that BASCOE underestimates the HALOE and POAM-III data.

both lower than 5\%. Between 50 and $100 \mathrm{hPa}$, the bias remains below $10 \%$ but the standard deviation increases to $90 \%$ at the Tropics and $20 \%$ at the other latitude bands (Fig. 5). Because aerosol and cirrus clouds at levels below $120 \mathrm{hPa}$ can seriously affect HALOE data, it is better to assess the quality of BASCOE analyses against other datasets less affected by Mie scattering, e.g. ozonesondes. This was done in the ASSET ozone intercomparison study (Geer et al., 2006). In that work it was shown that for levels below $100 \mathrm{hPa}, \mathrm{BASCOE}$ underestimates ozonesondes. For levels below $100 \mathrm{hPa}$ at the Tropics and levels below $200 \mathrm{hPa}$ in the Extra-tropics, this underestimation is around $50 \%$. This is due to the fact that BASCOE is not designed for the troposphere, does not include a proper parameterization of troposphere-stratosphere exchange, and is not tuned to adjust tropospheric ozone to more realistic values (e.g. from climatology).

Above $2 \mathrm{hPa}$, the bias increases and maximum is around $0.7 \mathrm{hPa}$. The highest bias is found at the Tropics where BASCOE underestimates HALOE by $11 \%$. As mentioned in Sect. 5.1, this is probably due to the set-up of the photolysis rate calculations. While significant, this bias is much smaller than the bias between BASCOE and MIPAS. This confirms the likely role of photolysis in the discrepancy since the local time of measurement between MIPAS and HALOE is different. At twilight (HALOE measurements), the impact of the photolysis rate calculation is less important on the ozone chemistry than during daytime (MIPAS measurements). Above $0.5 \mathrm{hPa}$, the standard deviation increases slightly, reflecting the increased variability in observed ozone due to its diurnal cycle at these levels.
During the 2003 ozone hole the bias between BASCOE and independent data is significant. The bias between BAS$\mathrm{COE}$ and POAM-III is around $100 \%$ at $100 \mathrm{hPa}$. However, the amount of ozone is so low that relative differences are no longer meaningful. In Fig. 6 we show a time series of POAM-III ozone averaged over two days for SH occultations and the corresponding BASCOE analyses. Ozone amounts are expressed as number densities to focus on the ozone hole altitude range. In general, BASCOE ozone is close to POAM-III data and the 2003 ozone hole observed by POAM-III is qualitatively well reproduced by BASCOE. However, differences between both datasets (not shown) reveal that BASCOE is not able to fully deplete ozone as suggested by the observations. For example, the lowest ozone number density observed by POAM-III at $16 \mathrm{~km}(\sim 75 \mathrm{hPa})$ occurred on the 14 October 2003 , is $\sim 1.9 \times 10^{11} \mathrm{molec} / \mathrm{cm}^{3}$ compared with $\sim 3.1 \times 10^{11} \mathrm{molec} / \mathrm{cm}^{3}$ shown by the analyses. This is in agreement with Geer et al. (2006, see their Fig. 23): while the BASCOE ozone hole is good compared to other assimilation system, BASCOE still overestimates ozonesondes at South Pole. Improving the ozone hole would require a better representation of the polar vortex barrier by increasing the model resolution and implementating a more advanced PSC parameterization (e.g., Chipperfield, 1999; Lefévre et al., 1998).

Ozone analyses during the 2002 ozone hole overestimate POAM-III: this is the only period where BASCOE disagrees qualitatively with POAM-III. This is due to the lack of MIPAS data from 29 September to 11 October 2002, combined with the difficulty of BASCOE, due to its relatively low resolution, to capture realistically the dynamical evolution during 
(a) O3 POAM3 @ South Pole [molec/cm3]

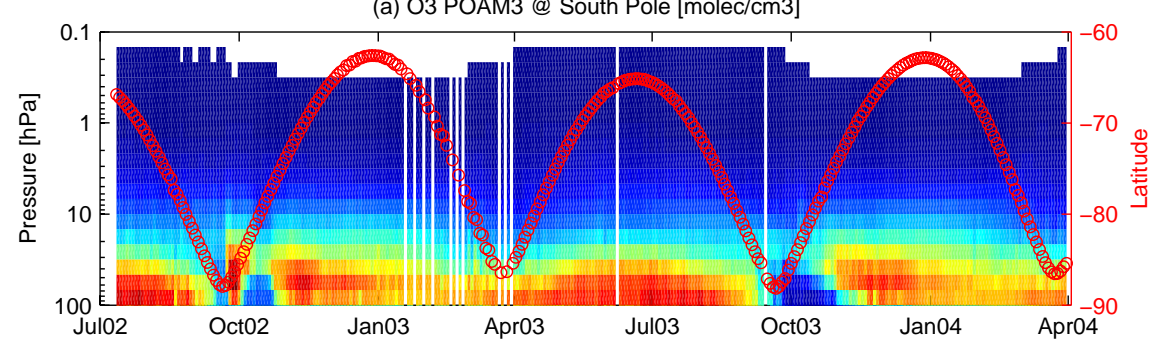

(b) O3 BASCOE @ POAM3 [molec/cm3]

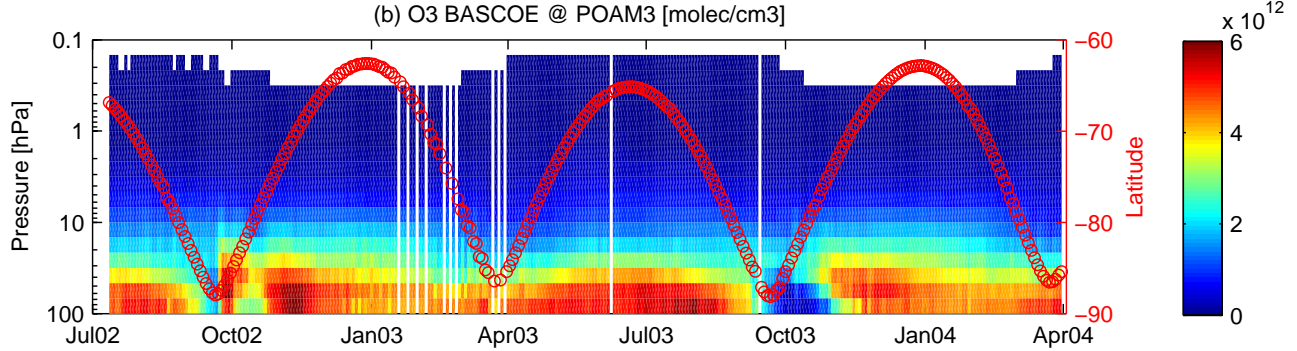

Fig. 6. Time series of POAM-III averaged over two days for ozone at South Pole (top), BASCOE ozone analyses at POAM-III (bottom), units of molec $/ \mathrm{cm}^{3}$. Red circles correspond to the average latitude of POAM-III observations (right y-axis).

the vortex split of 2002 (Newman and Nash, 2005). For example, averaged ozone observed by POAM-III at $68 \mathrm{hPa}$ is around $1.5 \times 10^{12} \mathrm{molec} / \mathrm{cm}^{3}$ while BASCOE analyses for the same period show values around $3.5 \times 10^{12} \mathrm{molec} / \mathrm{cm}^{3}$. Based on these statistics, we conclude there is satisfactory agreement between BASCOE analyses and independent data except during the 2002 Antarctic ozone hole. Using these statistics, the quality of the BASCOE ozone analyses has been estimated by combining the bias and standard deviation against HALOE and POAM-III (Table 1). No values are given for the 2002 Antarctic ozone hole since BASCOE values are qualitatively too different from independent observations.

\subsection{Estimation of differences between MIPAS and inde-} pendent observations using BASCOE analyses

Due to temporal variability and geographical gradients in atmospheric composition, temporal and spatial mismatches between two profile measurements can enhance dramatically the total error budget of their comparison and consequently preclude the intended determination of their bias and standard deviation. Thus, classical satellite-to-satellite comparisons are usually limited to pairs of profiles selected through pre-defined co-location criteria. For example, in their MIPAS ozone validation paper, Cortesi et al. (2007, hereafter denoted C2007) adopted a maximum geographical distance of $300 \mathrm{~km}$ and a maximum time difference of $3 \mathrm{~h}$ between the MIPAS and HALOE observations, yielding for the period from July 2002 to March 2004 a total of 141 profile pairs. The time and space interpolation capabilities offered by the data assimilation increase considerably the amount of co-located profiles that can be compared, since virtually all HALOE profiles can be used. The method consists in estimating differences between MIPAS data and independent observations using BASCOE as a transfer standard: (MIPAS - IndepObs $)=($ MIPAS - BASCOE $)-($ IndepObs - BAS COE), where IndepObs stand for HALOE and POAM-III. Note that Juckes (2007) has also compared MIPAS ozone observations against HALOE and POAM-III using analysed fields from a new assimilation algorithm, thus without using the transfer standard method.

Differences between MIPAS and HALOE data using this method are shown in Fig. 7a for the year 2003 and for five latitude bands. These results are based on 8311 HALOE profiles, compared to 141 co-located profiles found by $\mathrm{C} 2007$ in the validation paper of MIPAS ozone, i.e., we use 60 times more profiles. The differences between MIPAS and HALOE data using BASCOE analyses as a transfer standard are comparable to the results found by C2007: we also find that MIPAS data are almost always higher than HALOE with less than $+10 \%$ differences between $0.4 \mathrm{hPa}$ and $60 \mathrm{hPa}$, and less than $+5 \%$ differences between $3 \mathrm{hPa}$ and $20 \mathrm{hPa}$. Where the analyses are of poorer quality, i.e., near the model lid, in the troposphere and at the South Pole during the ozone hole, our method finds larger differences.

Differences between MIPAS and POAM-III data using BASCOE analyses as a transfer standard are shown in Fig. 7b for the year 2003 and for data from both hemispheres. These results are based on 7937 POAM-III profiles, compared with 1571 profiles in $\mathrm{C} 2007$, i.e., we use around 5 times more profiles. Again, our results are similar to those obtained by C2007: we find a bias below $\pm 5 \%$ between $0.5 \mathrm{hPa}$ and $50 \mathrm{hPa}$. At $100 \mathrm{hPa}$, the differences between MIPAS and 
Table 1. Estimate of the quality of BASCOE ozone analyses based on the combined bias and standard deviation against HALOE and POAM-III. A positive bias indicates that BASCOE globally overestimates HALOE and POAM-III. If not specified, the units are in percent.

\begin{tabular}{lllll}
\hline Altitude & Poles $^{\mathrm{a}}$ & Mid Latitudes $^{\mathrm{b}}$ & Tropics $^{\mathrm{c}}$ & 2003 Ozone hole \\
\hline $0.5 \mathrm{hPa}$ & $-15 \pm 15$ & $-7 \pm 10$ & $-10 \pm 7$ & - \\
$10 \mathrm{hPa}$ & $+3 \pm 7$ & $+3 \pm 5$ & $+2 \pm 5$ & - \\
$70 \mathrm{hPa}$ & $+11 \pm 12$ & $+10 \pm 13$ & $+4 \pm 30$ & $-3 \pm 3 \times 10^{11} \mathrm{molec} / \mathrm{cm}^{3}$ \\
Tropopause $^{\mathrm{e}}$ & $+30 \pm 30$ & $+40 \pm 80$ & $+45 \pm 70$ & - \\
\hline
\end{tabular}

a poleward of $60^{\circ} \mathrm{N}$ and $60^{\circ} \mathrm{S}$

b $30^{\circ} \mathrm{N}-60^{\circ} \mathrm{N}$ and $60^{\circ} \mathrm{S}-30^{\circ} \mathrm{S}$

c $30^{\circ} \mathrm{S}-30^{\circ} \mathrm{N}$

$\mathrm{d}$ poleward of $60^{\circ} \mathrm{S}$

e $100 \mathrm{hPa}$ at the Tropics, $200 \mathrm{hPa}$ at the Extra-Tropics

POAM-III found in C2007 increase to $+12 \%$ in the $\mathrm{NH}$ and $+15 \%$ in the SH. Again, this agrees with our results.

Differences between MIPAS and independent data from HALOE and POAM-III found here are comparable to those found by classical validation methods (e.g. C2007) when the assimilation system is able to reproduce accurately the MIPAS observations. In addition, our results are also comparable to those found by Juckes (2007). Values found here reinforce significantly the representativeness of those published by $\mathrm{C} 2007$ (especially in the comparison against HALOE data) since a much larger variety of atmospheric states and of measurements conditions are taken into account in the statistics presented in this paper.

\section{Nitrogen dioxide results}

In order to introduce the state of $\mathrm{NO}_{2}$ during the assimilation period, we show in Fig. 8 the time series of $\mathrm{NO}_{\mathrm{x}}$ derived from HALOE sunrise observations and the monitored BASCOE analyses. The agreement between HALOE and BASCOE $\mathrm{NO}_{\mathrm{x}}$ data is qualitatively good except at the South Pole for two periods of time where HALOE observed relatively high $\mathrm{NO}_{\mathrm{x}}$ concentrations. These periods occur in August 2003 and in December 2003. These periods correspond to enhancement of $\mathrm{NO}_{\mathrm{x}}$ by Energetic Particles Precipitation (EPP, Randall et al., 2007). The first period corresponds to mesospheric $\mathrm{NO}_{\mathrm{x}}$ production by precipitating electron of medium energy (Funke et al., 2005). The second period corresponds to mesospheric-stratospheric $\mathrm{NO}_{\mathrm{x}}$ production due to Solar Proton Events (SPEs) that took place from the end of October until mid November 2003 around Halloween (López-Puertas et al., 2005). The reason why BASCOE fails to reproduce these high $\mathrm{NO}_{\mathrm{x}}$ values is due to the fact that: (1) the production of $\mathrm{NO}_{\mathrm{x}}$ by EPP is not modelled in BASCOE, and (2) MIPAS high $\mathrm{NO}_{2}$ values are rejected by the data quality control filter. We discuss below how these special events influence the quality of the $\mathrm{NO}_{2}$ BASCOE analyses. (a) Bias (MIPAS-HALOE)

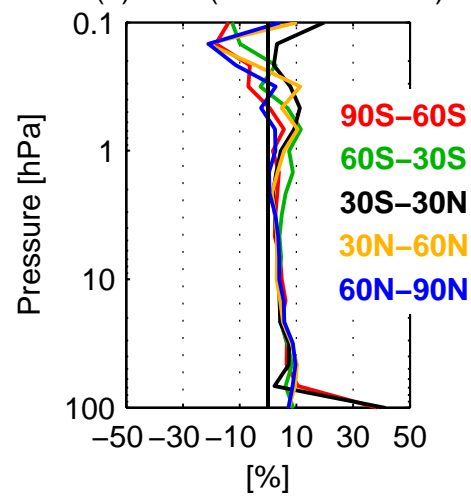

(b) Bias (MIPAS-POAM)

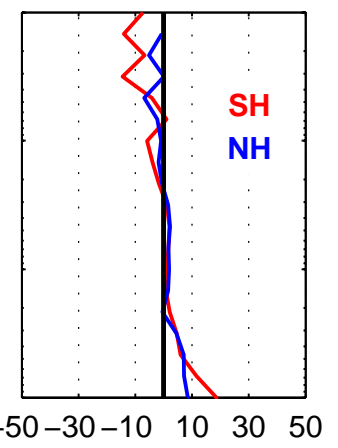

[\%]

Fig. 7. Ozone mean differences between MIPAS and HALOE (left) and MIPAS and POAM-III (right) using the BASCOE analyses as a transfer standard. The period is the year 2003. Each line correspond to a different latitude band. Positive values indicate that MIPAS overestimates the HALOE and POAM-III data.

\subsection{Consistency of analyses: BASCOE vs. MIPAS}

As for $\mathrm{O}_{3}$ (Fig. 1), Fig. 9 shows the zonal mean of $\mathrm{NO}_{2}$ observed by MIPAS and the corresponding analyses on 6 October 2003. In order to separate daytime and nighttime observations, the zonal mean is given for the ascending and descending phases of the satellite. Qualitatively, the consistency between MIPAS and BASCOE is good for both phases. The bias and standard deviation between assimilated MIPAS data and BASCOE analyses are given in Fig. 10 for MIPAS nighttime data. As for $\mathrm{O}_{3}$, we presents the statistics for the comparison between: (1) MIPAS assimilated data and BASCOE ("stat1n", where n stands for nighttime), (2) MIPAS all data and BASCOE ("stat2n") and (3) MIPAS all data and the control run ("stat3n"). The MIPAS errors (see Sect. 4) and the number of MIPAS observations per pressure bin and latitude band are also plotted. Here, we focus on a period where 
(a) NOx HALOE @ sunrise [ppbv]

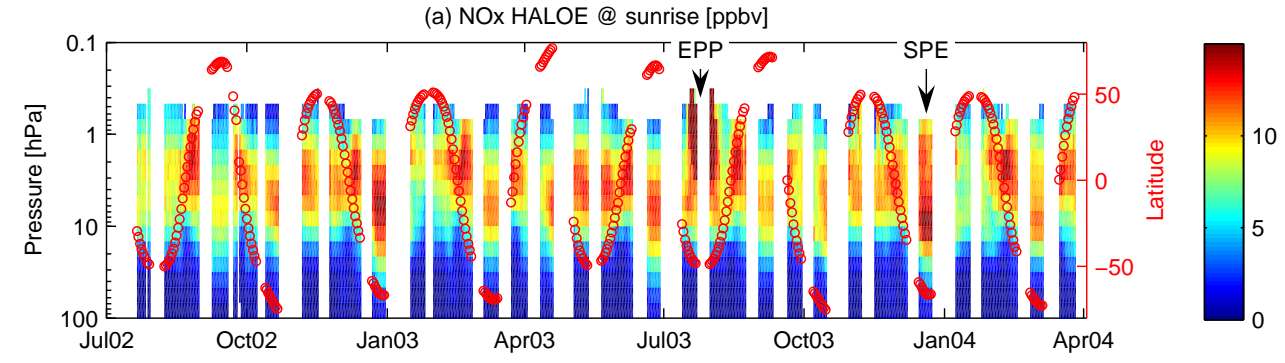

(b) NOx BASCOE @ HALOE [ppbv]

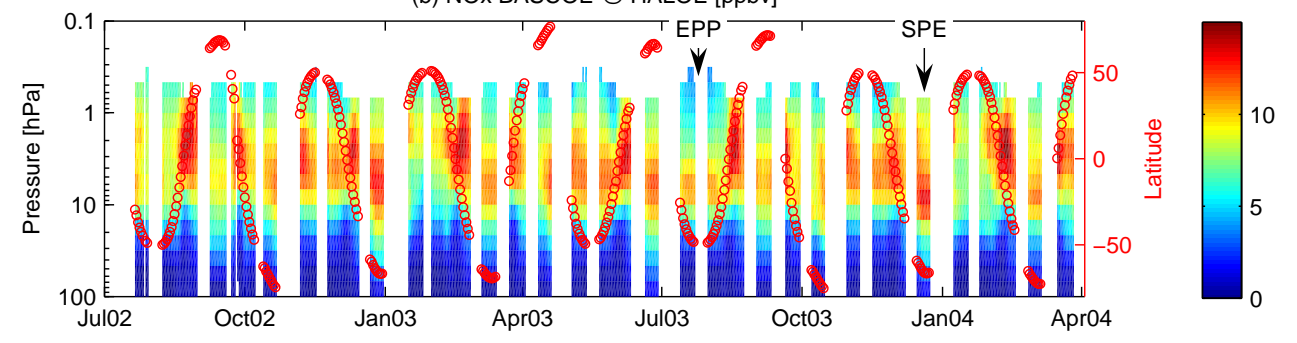

Fig. 8. Time series of HALOE sunrise daily averaged $\mathrm{NO}_{\mathrm{x}}$ (top) and BASCOE monitored $\mathrm{NO}_{\mathrm{x}}$ (bottom) in ppbv. Red circles correspond to the average latitude of HALOE observations (right y-axis).

(a) NO2 ascend

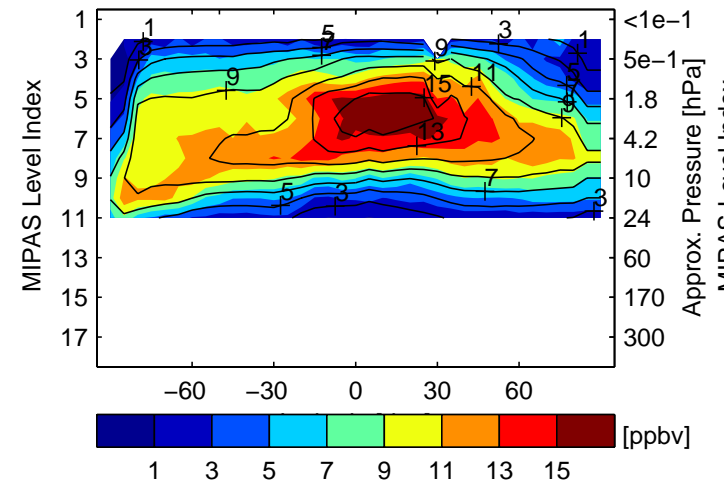

(b) NO2 descend

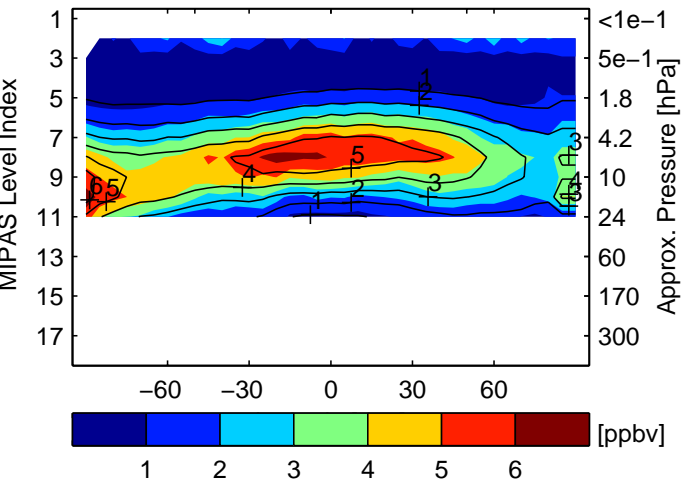

Fig. 9. Zonal mean of $\mathrm{NO}_{2}$ (ppbv) from MIPAS (isocontours) and BASCOE (isolines) for the ascending phase (i.e., nighttime measurements, Fig. 9a) and the descending phase (i.e., daytime measurements, Fig. 9b) of the satellite. The left-hand side vertical axis is the MIPAS vertical level index (1 highest, 17 lowest). Data are for 6 October 2003, and are averaged on a $5^{\circ}$ latitude grid.

$\mathrm{NO}_{\mathrm{x}}$ is not influenced by any EPP events, between 1 and 24 October 2003.

Except at the Poles, almost all nighttime observations are assimilated and there is little difference between stat $1 \mathrm{n}$ and stat2n. At the North Pole, around $40 \%$ of the observations are rejected above $3 \mathrm{hPa}$ but the bias and standard deviation between stat $1 \mathrm{n}$ and stat $2 \mathrm{n}$ remain close; some differences are visible only in the standard deviation above $0.7 \mathrm{hPa}$. A similar behaviour is found at the South Pole where the two statistics differ above $1 \mathrm{hPa}$. Hence, the data filter is set up correctly for stratospheric $\mathrm{NO}_{2}$ in normal conditions (not perturbed by EPP).
Above $10 \mathrm{hPa}$, bias of the BASCOE analyses is generally not significant except at the South Pole. Below $10 \mathrm{hPa}$, BASCOE overestimates MIPAS. Since the amount of $\mathrm{NO}_{\mathrm{x}}$ depends strongly on the surface area density of sulfate aerosols in this altitude region, this bias in the lower stratosphere is likely due to the model set up of sulfate aerosols. On the other hand, the standard deviation is almost always greater than the MIPAS random error. This is likely due to the observation operator where model values are interpolated to MIPAS locations for observations available around the BASCOE time step (see Sect. 3). Using time interpolation between model values at consecutive time steps should 


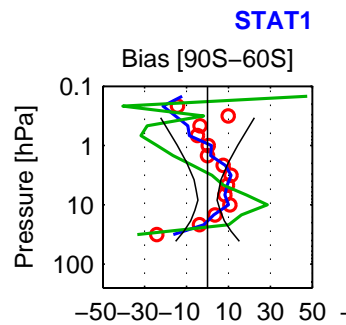

[\%]

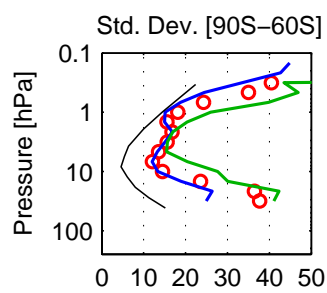

[\%]

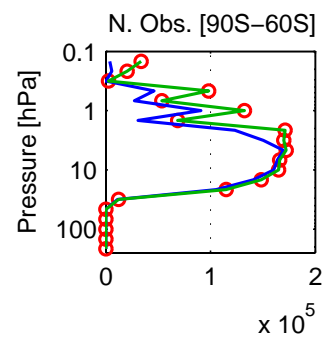

STAT2

Bias [60S-30S]

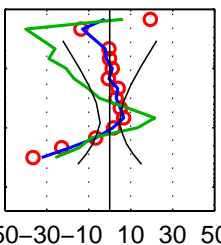

[\%]

Std. Dev. [60S-30S]

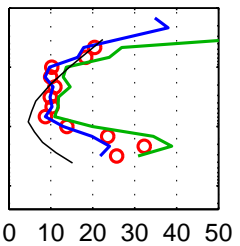

[\%]

N. Obs. [60S-30S]

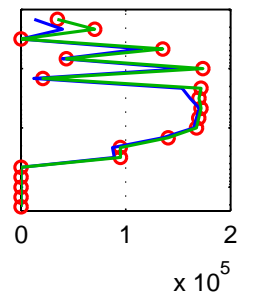

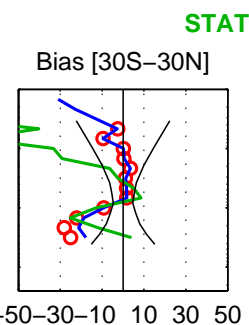

[\%]

Std. Dev. [30S-30N]

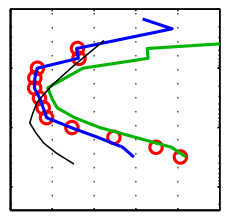

[\%]

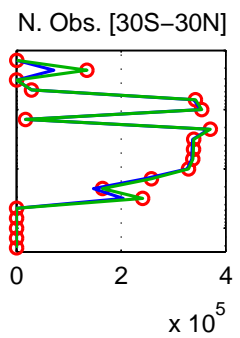

STAT3

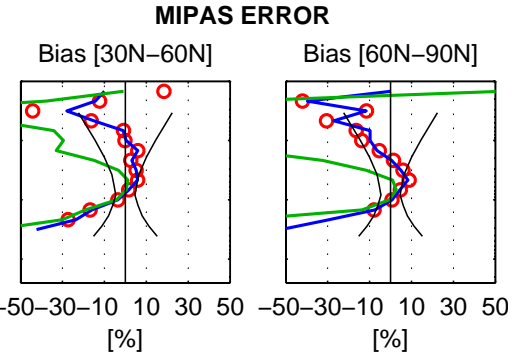

Std. Dev. [30N-60N]

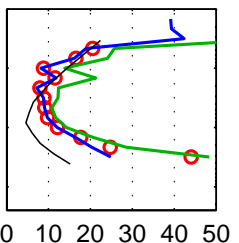

[\%]

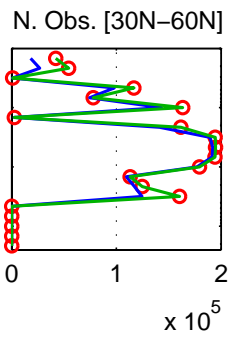

Std. Dev. [60N-90N]

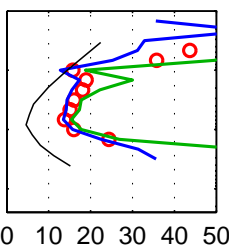

[\%]

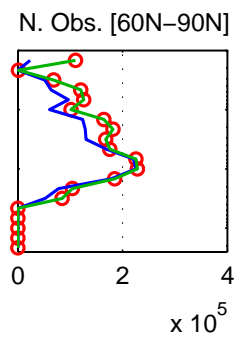

Fig. 10. As Fig. 2 but for nighttime MIPAS $\mathrm{NO}_{2}$ data and between 1 and 24 October 2003.

decrease the standard deviation between analyses and MIPAS. Nevertheless, a clear improvement is shown when one compares MIPAS with BASCOE (stat2) instead of the control run (stat3). This is even clearer when looking at statistics above $10 \mathrm{hPa}$. This illustrates the benefit of assimilating $\mathrm{NO}_{2}$ observations.

Similar conclusions can be drawn from statistics using MIPAS daytime observations, for which most observations are rejected above $1 \mathrm{hPa}$. On the other hand, even if these data are not filtered out, $\mathrm{NO}_{2}$ daytime errors are much larger than the background errors, and thus $\mathrm{NO}_{2}$ daytime data have little influence on the final analyses.

Time series of the bias and standard deviation for stat $1 \mathrm{n}$ are given in Fig. 11 for two pressure ranges and the five latitude bands. Outside the period/region of perturbed $\mathrm{NO}_{\mathrm{x}}$, the bias is generally in the range $[-1,7] \%$ and $[-15,7] \%$ at around $3 \mathrm{hPa}$ and $10 \mathrm{hPa}$, respectively. The corresponding standard deviation is below $15 \%$ and $20 \%$, respectively. Taking into account the MIPAS error and the absence of time interpolation in the observation operator, we find these values acceptable. During perturbed $\mathrm{NO}_{\mathrm{x}}$ periods, the bias and standard deviation can be very high, e.g., 50\%. This corresponds to the South Pole and the SH mid-latitudes between June and October 2003, and to the North Pole and NH mid-latitudes after the end of October 2003. For these cases, BASCOE underestimates MIPAS $\mathrm{NO}_{2}$.
On the other hand, from June until August at $10 \mathrm{hPa}$ and during June at $3 \mathrm{hPa}$, BASCOE overestimates MIPAS $\mathrm{NO}_{2}$ at $\mathrm{SH}$ mid-latitudes with a maximum bias of around $-30 \%$ and $-15 \%$, respectively (this was not revealed by the statistics shown in Fig. 10). This period corresponds to the South Polar Vortex, where values of $\mathrm{O}_{3}$ and $\mathrm{N}_{2} \mathrm{O}$, which drive $\mathrm{NO}_{2}$ production, are very low. Since the model resolution does not allow a vortex as isolated as it should be, BASCOE $\mathrm{NO}_{2}$ values are higher than the observations. This overestimate does not appear in the statistics at [60S-90S] because MIPAS observes the $\mathrm{NO}_{\mathrm{x}}$ perturbation by EPP at these latitudes. Thus, as for $\mathrm{O}_{3}$, BASCOE tends to overestimate $\mathrm{NO}_{2}$ in the Antarctic vortex during winter, likely due to the coarse horizontal resolution of the model.

To conclude this subsection, outside the period when stratospheric $\mathrm{NO}_{\mathrm{x}}$ is perturbed, and outside the polar vortex, the assimilation performs relatively well: no significant bias is found between BASCOE and MIPAS. Altough the standard deviation between BASCOE and MIPAS is higher than the MIPAS random error, a clear benefit is shown when the model is constrained by the observations. 

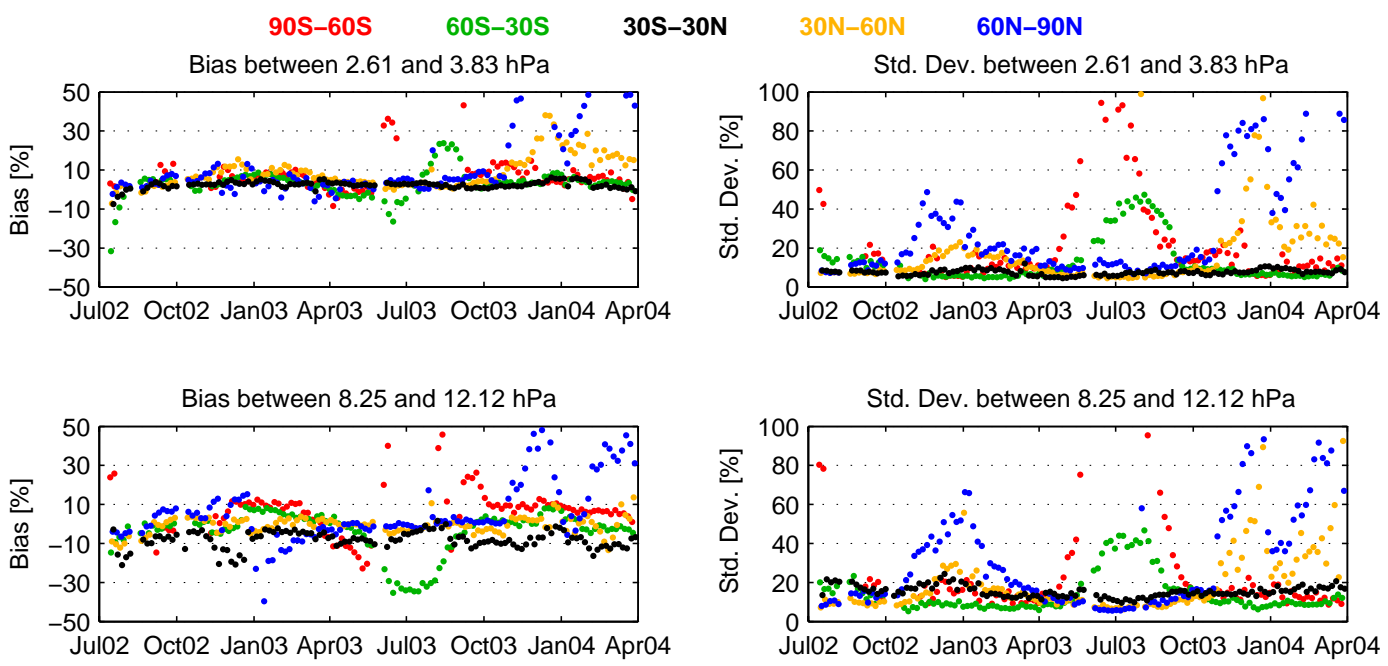

Fig. 11. As Fig. 3 but for nighttime MIPAS $\mathrm{NO}_{2}$ data. Each dot represents a five day average.

(a) NO2 POAM3 @ South Pole [ppbv]

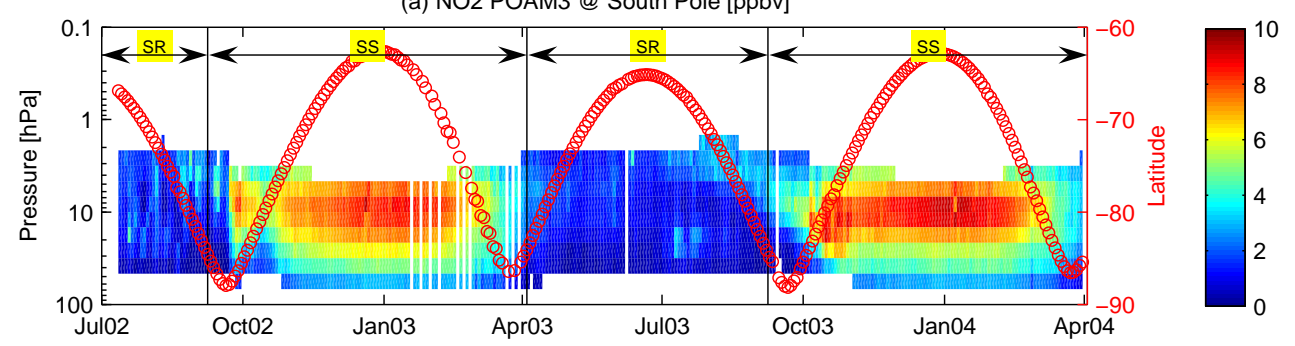

(b) NO2 BASCOE @ POAM3 [ppbv]

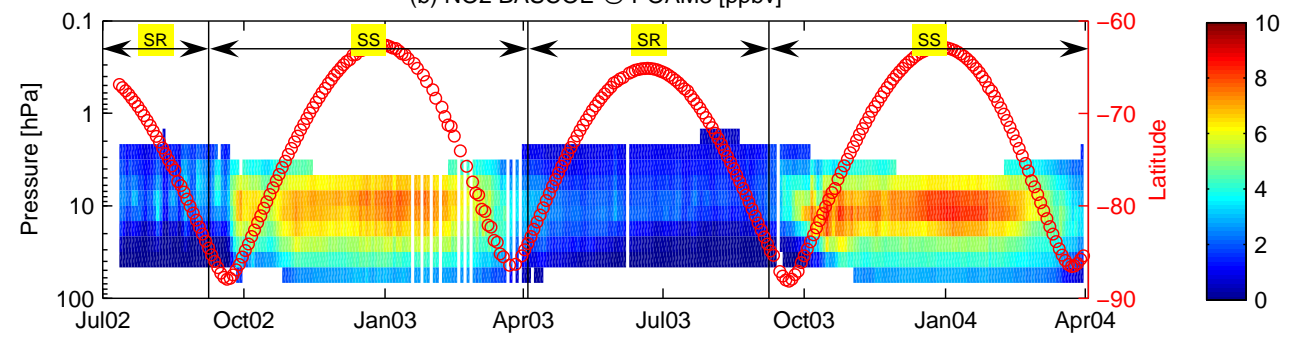

Fig. 12. Time series of POAM-III NO 2 averaged over two days for $\mathrm{NO}_{2}$ at South Pole (top) and $\mathrm{BASCOE}$ monitoring $\mathrm{NO}_{2}$ analyses (bottom) in ppbv. The horizontal arrows identify periods of sunrise (SR) and sunset (SS) observations from POAM-III. Red circles correspond to the average latitude of POAM-III observations (right y-axis).

6.2 Validation of analyses: BASCOE vs. independent observations

HALOE and POAM-III data have been monitored by BASCOE during the assimilation of MIPAS data. Time series of $\mathrm{NO}_{2}$ observed by POAM-III at the South Pole and the monitoring analyses are given in Fig. 12 (see Fig. 8 for the analogous comparison between HALOE $\mathrm{NO}_{\mathrm{x}}$ and BASCOE $\mathrm{NO}_{\mathrm{x}}$ ). Also indicated is the measurement mode, local sunrise (SR) or local sunset (SS). $\mathrm{NO}_{2}$ time series show a seasonal cycle with relatively low $\mathrm{NO}_{2}$ during the $\mathrm{SH}$ winter (JuneAugust) and higher values during SH summer (DecemberFebruary). The NH time series also exhibits such a cycle (not shown). Low winter $\mathrm{NO}_{2}$ is due to the presence of the polar vortex barrier which makes it difficult for $\mathrm{N}_{2} \mathrm{O}$, the $\mathrm{NO}_{2}$ source gas, to reach the Pole. Moreover, during sunrise, NO increases rapidly while $\mathrm{NO}_{2}$ decreases and most of the $\mathrm{NO}_{\mathrm{x}}$ is thus in the form of NO (Randall et al., 2007). Conversely, during sunset observations, $\mathrm{NO}_{\mathrm{x}}$ has relatively higher concentrations of $\mathrm{NO}_{2}$. Thus, the switch of the occultation mode 


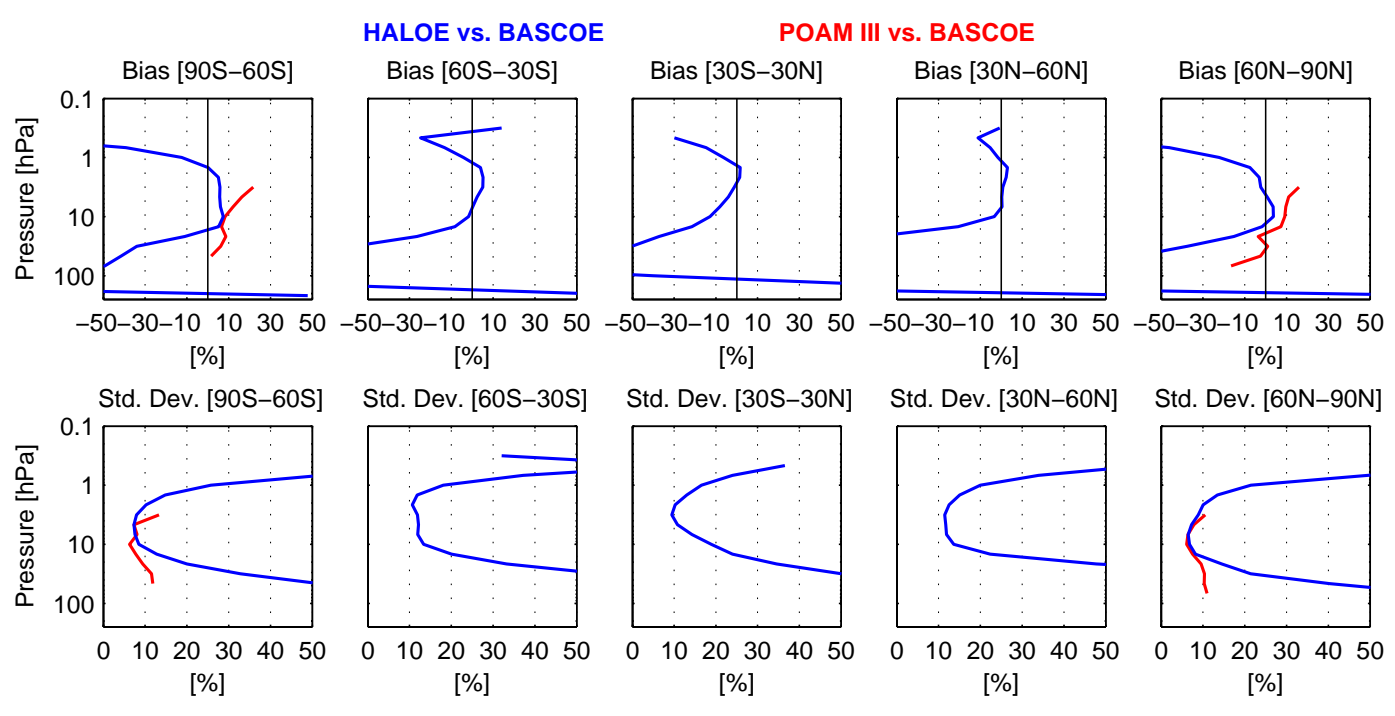

Fig. 13. Bias and standard deviation between HALOE $\mathrm{NO}_{\mathrm{x}}$ and $\mathrm{BASCOE} \mathrm{NO}_{\mathrm{x}}$ (blue), and POAM-III NO $\mathrm{NO}_{2}$ and $\mathrm{BASCOE} \mathrm{NO}_{2}$ (red). Comparison against HALOE is done for a period where stratospheric $\mathrm{NO}_{\mathrm{x}}$ was not perturbed by EPP production (see text for details). Comparisons against POAM-III are done at local sunset, between November 2003 and February 2004 in SH, and between May and August 2003 in NH. Positive values of the bias indicate that BASCOE underestimates the HALOE and POAM-III data.

of POAM-III around the Equinox (see Sect. 3.3) increases the seasonal variation of $\mathrm{NO}_{2}$ given by the instrument.

BASCOE also exhibits this seasonal variation, in good qualitative agreement with the POAM-III data. From July to October 2003, POAM-III observes a thin tongue of relatively high $\mathrm{NO}_{2}$ descending from 2 to $10 \mathrm{hPa}$. This is the signature of the EPP event discussed above. The effects of the EPP are more apparent in the HALOE observations than in the POAM-III observations (see Fig. 8). The reasons for this are: (1) POAM-III observations throughout most of the winter are done at sunrise, a time when most of the $\mathrm{NO}_{\mathrm{x}}$ is in the form of NO, and (2) no POAM-III observations are available above $2 \mathrm{hPa}$. This explains why the enhanced level of $\mathrm{NO}_{2}$ is not significantly higher than the background level. The tongue of relatively high $\mathrm{NO}_{2}$ is not reproduced by BASCOE for the reasons discussed above.

The bias and standard deviation between BASCOE and independent observations from HALOE $\left(\mathrm{NO}_{\mathrm{x}}\right)$ and POAM-III $\left(\mathrm{NO}_{2}\right)$ are given in Fig. 13. Comparison with HALOE is done for a period where stratospheric $\mathrm{NO}_{\mathrm{x}}$ was not perturbed by EPP production, i.e., from August 2002 until March 2004, excluding the periods May-August 2003 and the period of the Halloween SPE. During this period, the bias between HALOE and BASCOE is generally below $\pm 10 \%$ (in magnitude) in the pressure range $1-10 \mathrm{hPa}$, where the $\mathrm{NO}_{\mathrm{x}}$ mixing ratio is maximum (Fig. 8). The standard deviation is minimum at the $\mathrm{NO}_{\mathrm{x}}$ maximum (around $5 \mathrm{hPa}$ ) with values below or close to $10 \%$. Below $10 \mathrm{hPa}$, we provide the bias and standard deviation in number densities, since the amount of $\mathrm{NO}_{2}$ becomes relatively low. Around $30 \mathrm{hPa}$, BASCOE overestimates HALOE and we find that the bias and standard devia- tion do not exceed $-0.8 \pm 0.8$ ppbv. Considering the HALOE errors, which are between 10 and $15 \%$ in the middle stratosphere (Gordley et al., 1996), we find no significant bias between the BASCOE analyses and HALOE data.

For reasons given above, comparisons against POAM-III in Fig. 13 are only done during summer, a time when the amount of observed $\mathrm{NO}_{2}$ is significant. This corresponds to May-August 2003 for the NH comparison and to NovemberFebruary 2003/2004 for the SH comparison (which is relatively similar to the statistics based on November-February 2002/2003). The bias between BASCOE and POAM-III is higher than that between BASCOE and HALOE, being around $10 \%$ at the $\mathrm{NO}_{2}$ peak $(10 \mathrm{hPa}$, see Fig. 12).

Maximum bias is observed in the $\mathrm{SH}$ at $3 \mathrm{hPa}(22 \%)$. The standard deviation is always below $15 \%$. Based on POAMIII uncertainties (typically below 12\%), this suggests a significant bias above $5 \mathrm{hPa}$ in both hemispheres. Below that level, no significant bias between BASCOE $\mathrm{NO}_{2}$ analyses and POAM-III $\mathrm{NO}_{2}$ observations is observed.

Table 2 provides an estimation of the quality of BASCOE $\mathrm{NO}_{\mathrm{x}}$ based on the biases and standard deviations against HALOE. POAM-III data were not used to build this table since it is difficult to interpret disagreements between the differences BASCOE-POAM-III and BASCOE-HALOE. We also only consider periods when the stratosphere is unperturbed by EPP events, meaning that this table is not valid either during the SH 2003 winter or during the Halloween 2003 SPE. 
Table 2. Estimate of the quality of BASCOE $\mathrm{NO}_{\mathrm{x}}$ analyses based on bias and standard deviation against HALOE for periods when the stratosphere is unperturbed by EPP. This table is then not valid either during the SH 2003 winter or during the Halloween 2003 SPE. If not specified, the units are in percent.

\begin{tabular}{llll}
\hline Altitude & Poles $^{\mathrm{a}}$ & Mid Latitudes $^{\mathrm{b}}$ & Tropics $^{\mathrm{c}}$ \\
\hline $1 \mathrm{hPa}$ & $+20 \pm 25$ & $-8 \pm 20$ & $+5 \pm 16$ \\
$5 \mathrm{hPa}$ & $-5 \pm 8$ & $-2 \pm 12$ & $+0 \pm 10$ \\
$30 \mathrm{hPa}$ & $+0.4 \pm 0.8 \mathrm{ppbv}$ & $+0.8 \pm 0.6 \mathrm{ppbv}$ & $+0.4 \pm 0.4 \mathrm{ppbv}$ \\
\hline
\end{tabular}

a poleward of $60^{\circ} \mathrm{N}$ and $60^{\circ} \mathrm{S}$

b $30^{\circ} \mathrm{N}-60^{\circ} \mathrm{N}$ and $60^{\circ} \mathrm{S}-30^{\circ} \mathrm{S}$

c $30^{\circ} \mathrm{S}-30^{\circ} \mathrm{N}$

(a) Bias (MIPAS-HALOE)

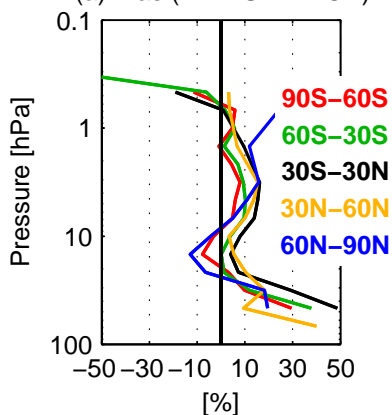

[\%] (b) Bias (MIPAS-POAM)

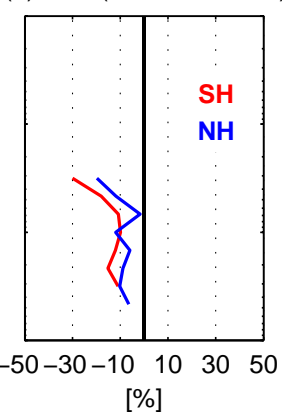

Fig. 14. Nitrogen dioxide mean differences between MIPAS and HALOE (left) and MIPAS and POAM-III (right) using the BAS$\mathrm{COE}$ analyses as a transfer standard. The periods considered are identical as in Fig. 13. Each line correspond to a different latitude band. Positive values indicate that MIPAS overestimates the HALOE and POAM-III data.

6.3 Estimation of differences between MIPAS and independent observations using BASCOE analyses

Using BASCOE as a transfer standard (see Sect. 5.3), we estimate the difference between MIPAS and independent observations from HALOE and POAM-III. In the pressure range $2-20 \mathrm{hPa}$, differences between MIPAS and HALOE are between $\pm 13 \%$ depending on the latitude band and the pressure level (Fig. 14a). Again, this comparison adresses a period when stratospheric $\mathrm{NO}_{\mathrm{x}}$ was not perturbed by EPP production. The validation study of MIPAS $\mathrm{NO}_{2}$ performed by Wetzel et al. (2007, hereafter denoted W2007) found that MIPAS was high with respect to HALOE over the Antarctic, the southern mid-latitudes and the northern mid-latitudes. For these regions, our results agree with W2007. W2007 find that over the Arctic, MIPAS is low with respect to HALOE. This is not the case here, but the bias over the Arctic is lower than for other latitude bands for levels below $3 \mathrm{hPa}$. (Note that W2007 do not provide any comparison between MIPAS and HALOE for the Tropics.) Excluding the Tropics, and

between 2 and $10 \mathrm{hPa}$, the highest bias between MIPAS and HALOE found by W2007 is $+20 \%$ at $2 \mathrm{hPa}$ in the middle latitudes for both hemispheres, and the lowest bias found by W2007 is $-5 \%$ at $10 \mathrm{hPa}$ over the Arctic. In general, our values are 5\% higher than those found by W2007. We remark that W2007 find 260 HALOE co-located profiles, while we base our results on 6000 HALOE profiles.

Differences between MIPAS $\mathrm{NO}_{2}$ and POAM-III $\mathrm{NO}_{2}$ using BASCOE as a transfer standard are given in Fig. 14b. We only provide comparisons for POAM-III sunset data for both hemispheres (as in Fig. 13b), i.e., a NH comparison for MayAugust 2003 and a SH comparison for November-February 2003/2004. Figure 10 suggests that MIPAS underestimates POAM-III between $[-15,-6] \%$. W2007 estimate the differences between MIPAS and POAM-III for different periods of time. Two of the periods they choose are close in time to our choice of period: (1) April-June 2003 for NH colocations; (2) October-December for SH co-locations (see Fig. 11 in W2007). For these cases, they find 36 and 125 co-located profiles, respectively, which have to be compared with 605 and 651 profiles in our case. Differences between MIPAS and POAM-III found here agree with the values from W2007 for NH data: W2007 found MIPAS to be relatively low compared to POAM-III, between $[-15,-10] \%$ for levels above $10 \mathrm{hPa}$. For SH data, W2007 found that the bias between MIPAS and POAM-III is negative $(-10 \%)$ at $3 \mathrm{hPa}$; they found a positive bias of $+15 \%$ at $10 \mathrm{hPa}$. For these two cases, W2007 find that MIPAS and POAM-III agree within their combined errors. The differences between MIPAS and POAM-III found here also agree within the combined errors of the two instruments. In the pressure range $3-10 \mathrm{hPa}$, the transfer standard method gives differences between instruments in agreement with those given by classical validation methods (e.g. W2007). Moreover, the transfer standard method brings together all the HALOE and POAM-III data, extending the W2007 conclusions to a much larger variety of atmospheric states and measurement conditions. 


\section{Conclusions}

In this paper we evaluate the performance of BASCOE ozone and nitrogen dioxide analyses produced by assimilation of ENVISAT MIPAS data. Although such data had already been assimilated before, previous studies focused on relatively short assimilation periods, typically a few months, especially for $\mathrm{NO}_{2}$. In contrast, the assimilation period addressed by our study covers the entire 21 months (July 2002March 2004) during which MIPAS operated at its nominal resolution. As well as providing an extended assimilation period the analyses are evaluated by monitoring independent data from HALOE and POAM-III. A seven-month free model run of the BASCOE CTM, starting in May 2003, is used as a control run to evaluate the benefit of the assimilation. Finally, BASCOE analyses are used to estimate differences between MIPAS data and HALOE and POAM-III data.

$\mathrm{O}_{3}$ analyses are found to agree with MIPAS ozone data within the MIPAS errors. Comparison between the analyses and a free model run shows that the benefit of the assimilation is significant during the Antarctic ozone hole and in the lower stratosphere. In other regions, the free model run agrees with the MIPAS data within the MIPAS error bars; thus, while the difference against MIPAS is reduced by the assimilation, this does not provide significant improvement over the free model run. The gain from the assimilation is observed in regions where the model is known to have deficiencies. Comparison against independent data from HALOE and POAMIII shows that the analyses are within the instrumental errors of the independent data. Using BASCOE ozone analyses as a transfer standard, estimates of the biases between MIPAS and HALOE, and between MIPAS and POAM-III, generally agree with values deduced by classical validation approaches which limit comparison to direct geographical co-location of the measurements. The main advantage of our method is that it increases the number of correlative independent data used to validate MIPAS data; it thus extends and reinforces the classical validation results, as a much larger variety of atmospheric states and of measurement conditions are taken into account.

The behaviour of the $\mathrm{NO}_{2}$ analyses is more difficult to interpret because during part of the assimilation period, the stratosphere was perturbed by $\mathrm{NO}_{\mathrm{x}}$ production from Energetic Particles Precipitation (EPP) events. During the periods of unperturbed stratospheric $\mathrm{NO}_{\mathrm{x}}$, and around the $\mathrm{NO}_{2}$ peak $(1-10 \mathrm{hPa})$, the bias between BASCOE and MIPAS is not significant but the standard deviation of their differences is greater than the MIPAS random error. Improving the assimilation of $\mathrm{NO}_{2}$ would require a model-to-observation operator that, in addition to spatial interpolation from model grid point to the observation location, includes a time interpolation from consecutive model time steps to the observation time. Comparison of BASCOE $\mathrm{NO}_{2}$ analyses with HALOE and POAM-III independent $\mathrm{NO}_{2}$ data shows the former to be qualitatively good (within the instrumental errors of the independent data) outside the time period and region perturbed by EPP events. Differences between MIPAS $\mathrm{NO}_{2}$ data and independent HALOE and POAM-III $\mathrm{NO}_{2}$ data are derived using BASCOE analyses; they agree with results from the classical method limited to co-located measurements only. As for ozone, this extends and reinforces previous results on the validity of the MIPAS data.

This study has revealed several weaknesses in the model, or in the set-up of the system, that can degrade the analyses: (1) the model resolution is too coarse to describe accurately dynamical barriers like the tropical surf zone or the Polar Vortex; this problem can be solved by increasing the horizontal resolution of the model. (2) The online data filter rejects most of the MIPAS $\mathrm{NO}_{2}$ observations during EPP events; better formulations of this filter, or off-line filtering of the observations, would alleviate this. A parameterization describing the effect of the EPP on $\mathrm{NO}_{\mathrm{x}}$ in the model would also improve the $\mathrm{NO}_{2}$ analyses. (3) It was found that ozone analyses around $0.5 \mathrm{hPa}$ underestimate the observations (both assimilated and independent). This is likely due to the formulation of the photolysis rate calculations and the fact that $0.5 \mathrm{hPa}$ is close to the model lid $(0.1 \mathrm{hPa})$. We plan to perform experiments to test this hypothesis by using ECMWF wind data posterior to 2006, when ECMWF raised the model top up to $0.01 \mathrm{hPa}$.

BASCOE $\mathrm{O}_{3}$ analyses are part of the PROMOTE project and are publicly available via the BASCOE website (www. bascoe.oma.be/promote). BASCOE $\mathrm{NO}_{2}$ analyses and other analysed fields (the latter not yet validated) can be obtained on request by emailing the first author of this paper.

Acknowledgements. We thank M. Chipperfield for providing initial fields from the SLIMCAT CTM; the POAM-III and HALOE teams for making their data available to us; and K. Hoppel for helping to interpret the POAM-III data. Q. Errera, S. Chabrillat and J.-C. Lambert are supported by the Belgian Federal Science Policy in the framework of the BASCOE ProDEx project for QE and SC (PEA 90125) and the CINAMON ProDEx project for JCL (PEA C 15151).

Edited by: W. Ward

\section{References}

Baier, F., Erbertseder, T., Morgenstern, O., Bittner, M., and Brasseur, G.: Assimilation of MIPAS observations using a threedimensional global chemistry-transport model, Q. J. Roy. Meteor. Soc., 131, 3529-3542, doi:10.1256/qj.05.92, 2005.

Bhatt, P. P., Remsberg, E. E., Gordley, L. L., McInerney, J. M., Brackett, V. G., and Russell III, J. M.: An evaluation of the quality of Halogen Occultation Experiment ozone profiles in the lower stratosphere, J. Geophys. Res., 104, 9261-9276, doi: 10.1029/1999JD900058, 1999. 
Bouttier, F. and Courtier, P.: Data assimilation concepts and methods, March 1999, in: Meteorological Training Course Lecture Series, ECMWF, 2002.

Brühl, C., Drayson, S. R., Russell, J. M., Crutzen, P. J., McInerney, J. M., Purcell, P. N., Claude, H., Gernandt, H., McGee, T. J., McDermid, I. S., and Gunson, M. R.: Halogen Occultation Experiment ozone channel validation, J. Geophys. Res., 101, 10217 10 240, doi:10.1029/95JD02031, 1996.

Chipperfield, M. P.: Multiannual simulations with a threedimensional chemical transport model, J. Geophys. Res., 103, 1781-1805, 1999.

Chipperfield, M. P., Khattatov, B. V., and Lary, D. J.: Sequential assimilation of stratospheric chemical observations in a threedimensional model, J. Geophys. Res., 107, 4585, doi:10.1029/ 2002JD002110, 2002.

Cortesi, U., Lambert, J. C., De Clercq, C., Bianchini, G., Blumenstock, T., Bracher, A., Castelli, E., Catoire, V., Chance, K. V., De Mazière, M., Demoulin, P., Godin-Beekmann, S., Jones, N., Jucks, K., Keim, C., Kerzenmacher, T., Kuellmann, H., Kuttippurath, J., Iarlori, M., Liu, G. Y., Liu, Y., McDermid, I. S., Meijer, Y. J., Mencaraglia, F., Mikuteit, S., Oelhaf, H., Piccolo, C., Pirre, M., Raspollini, P., Ravegnani, F., Reburn, W. J., Redaelli, G., Remedios, J. J., Sembhi, H., Smale, D., Steck, T., Taddei, A., Varotsos, C., Vigouroux, C., Waterfall, A., Wetzel, G., and Wood, S.: Geophysical validation of MIPAS-ENVISAT operational ozone data, Atmos. Chem. Phys., 7, 4807-4867, 2007, http://www.atmos-chem-phys.net/7/4807/2007/.

Daerden, F., Larsen, N., Chabrillat, S., Errera, Q., Bonjean, S., Fonteyn, D., Hoppel, K., and Fromm, M.: A 3D-CTM with detailed online PSC-microphysics: analysis of the Antarctic winter 2003 by comparison with satellite observations, Atmos. Chem. Phys., 7, 1755-1772, 2007,

http://www.atmos-chem-phys.net/7/1755/2007/.

Damian, V., Sandu, A., Damian, M., Potra, F., and Carmichael, G.: The Kinetic PreProcessor KPP - A Software Environment for Solving Chemical Kinetics, Comput. Chem. Eng., 26, 15671579, 2002.

Dethof, A.: Assimilation of ozone retrievals from the MIPAS instrument on board ENVISAT, Technical Memorandum 428, ECMWF, Reading, UK, 2003.

Erbertseder, T., Baier, F., Errera, Q., Viscardy, S., Schwinger, J., and Elbern, H.: The Promote Ozone Profile Service - Long-Term 3d Ozone Reanalysis Of ERS-2 And Envisat Data Sets, in: ESA Special Publication SP636: Proceedings of Envisat Symposium 2007, available online: http://earth.esa.int/workshops/envisatsymposium/ proceedings/sessions/5A1/463750er.pdf, 2007.

Errera, Q. and Fonteyn, D.: Four-dimensional variational chemical assimilation of CRISTA stratospheric measurements, J. Geophys. Res., 106, 12 253-12 265, 2001.

Errera, Q., Bonjean, S., Chabrillat, S., Daerden, F., and Viscardy, S.: BASCOE Assimilation of Ozone and Nitrogen Dioxide observed by MIPAS and GOMOS: Comparison Between the Two Sets of Analyses, in: ESA Special Publication SP-636: Proceedings of Envisat Symposium 2007, available online: http://earth.esa.int/workshops/envisatsymposium/ proceedings/sessions/2A3/463880er.pdf, 2007.

Fischer, H., Birk, M., Blom, C., Carli, B., Carlotti, M., von Clarmann, T., Delbouille, L., Dudhia, A., Ehhalt, D., Endemann, M.,
Flaud, J. M., Gessner, R., Kleinert, A., Koopman, R., Langen, J., López-Puertas, M., Mosner, P., Nett, H., Oelhaf, H., Perron, G., Remedios, J., Ridolfi, M., Stiller, G., and Zander, R.: MIPAS: an instrument for atmospheric and climate research, Atmos. Chem. Phys., 8, 2151-2188, 2008,

http://www.atmos-chem-phys.net/8/2151/2008/.

Fonteyn, D., Bonjean, S., Chabrillat, S., Daerden, F., and Errera, Q.: 4D-VAR Chemical Data Assimilation of ENVISAT Chemical Products (BASCOE): Validation Support Issues, in: ESA Special Publication SP-531: Procedings of First Envisat Validation Workshop, available online: http://envisat.esa.int/pub/ESA_DOC/envisat_val_1202/ proceedings/ACV/data_assim/07_fonteyn.pdf, 2002.

Fonteyn, D., Lahoz, W., Geer, A., Dethof, A., Wargan, K., Stajner, L., Pawson, S., Rood, R., Bonjean, S., Chabrillat, S., Daerden, F., and Errera, Q.: MIPAS ozone assimilation, in: ESA Special Publication SP-562: Second Workshop on the Atmospheric Chemistry Validation of ENVISAT (ACVE-2), available online: http: //envisat.esa.int/workshops/acve2/papers/EMI01DF.pdf, 2004.

Funke, B., López-Puertas, M., Gil-López, S., von Clarmann, T., Stiller, G. P., Fischer, H., and Kellmann, S.: Downward transport of upper atmospheric $\mathrm{NOx}$ into the polar stratosphere and lower mesosphere during the Antarctic 2003 and Arctic 2002/2003 winters, J. Geophys. Res., 110, D24308, doi:10.1029/ 2005JD006463, 2005.

Gauthier, P., Chouinard, C., and Brasnett, B.: Quality Control: methodology and applications, in: Data Assimilation for the Earth System, edited by: Swinbank, R., Shutyaev, V., and Lahoz, W. A., NATO Science Series, Kluwer Academic Publisher, 177-187, 2003.

Geer, A. J., Lahoz, W. A., Bekki, S., Bormann, N., Errera, Q., Eskes, H. J., Fonteyn, D., Jackson, D. R., Juckes, M. N., Massart, S., Peuch, V.-H., Rharmili, S., and Segers, A.: The ASSET intercomparison of ozone analyses: method and first results, Atmos. Chem. Phys., 6, 5445-5474, 2006,

http://www.atmos-chem-phys.net/6/5445/2006/.

Gilbert, J.-C. and Lemarechal, C.: Some numerical experiments with variable storage quasi-Newton algorithms, Math. Prog., 45, 407-435, 1989.

Gordley, L. L., Russell III, J. M., Mickley, L. J., Frederick, J. E., Park, J. H., Stone, K. A., Beaver, G. M., McInerney, J. M., Deaver, L. E., Toon, G. C., Murcray, F. J., Blatherwick, R. D., Gunson, M. R., Abbatt, J. P. D., Mauldin III, R. L., Mount, G. H, Sen, B., and Blavier, J.-F.: Validation of nitric oxide and nitrogen dioxide measurements made by the Halogen Occultation Experiment for UARS platform, J. Geophys. Res., 101, 10 240-10 266, 1996.

Hairer, E. and Wanner, G.: Solving Ordinary Differential Equations II. Stiff and Differential - Algebraic Problems, Springer, 1996.

Ide, K., Courtier, P., Ghil, M., and Lorenc, A.: Unified notation for data assimilation: Operational sequential and variational, J. Meteorol. Soc. Jpn, 75, 181-189, 1997.

Juckes, M. N.: An annual cycle of long lived stratospheric gases from MIPAS, Atmos. Chem. Phys., 7, 1879-1897, 2007, http://www.atmos-chem-phys.net/7/1879/2007/.

Kalnay, E.: Atmospheric modeling, data assimilation and predictability, Cambridge University Press, UK, 2003.

Lahoz, W. A., Errera, Q., Swinbank, R., and Fonteyn, D.: Data assimilation of stratospheric constituents: a review, Atmos. Chem. 
Phys., 7, 5745-5773, 2007, http://www.atmos-chem-phys.net/7/5745/2007/.

Lefévre, F., Figarol, F., Carslaw, K. S., and Peter, T.: The 1997 Arctic ozone depletion quantified from three-dimensional model simulations, Geophys. Res. Lett., 25, 2425-2428, 1998.

Lin, S.-J. and Rood, R. B.: Multidimensional flux-form semiLagrangian transport schemes, Mon. Weather Rev., 124, 20462070, 1996.

López-Puertas, M., Funke, B., Gil-López, S., von Clarmann, T., Stiller, G. P., Höpfner, M., Kellmann, S., Fischer, H., and Jackman, C. H.: Observation of NOx enhancement and ozone depletion in the Northern and Southern Hemispheres after the OctoberNovember 2003 solar proton events, J. Geophys. Res., 110, A09S43, doi:10.1029/2005JA011050, 2005.

Lucke, R. L., Korwan, D. R., Bevilacqua, R. M., Hornstein, J. S., Shettle, E. P., Chen, D. T., Daehler, M., Lumpe, J. D., Fromm, M. D., Debrestian, D., Neff, B., Squire, M., König-Langlo, G., and Davies, J.: The Polar Ozone and Aerosol Measurement (POAM) III instrument and early validation results, J. Geophys. Res., 104, 18 785-18 800, doi:10.1029/1999JD900235, 1999.

Lumpe, J. D., Bevilacqua, R. M., Hoppel, K. W., and Randall, C. E.: POAM III retrieval algorithm and error analysis, J. Geophys. Res., 107(D21), 4575, doi:10.1029/2002JD002137, 2002.

Nazaryan, H., McCormick, M., and Russell III, J.: New studies of SAGE II and HALOE ozone profile and long-term change comparisons, J. Geophys. Res., 110, D09305, doi:10.1029/ 2004JD005425, 2005.

Newman, P. A. and Nash, E. R.: The Unusual Southern Hemisphere Stratosphere Winter of 2002, J. Atmos. Sci., 62, 614-628, 2005.

Randall, C. E., Lumpe, J. D., Bevilacqua, R. M., Hoppel, K. W., Shettle, E. P., Rusch, D. W., Gordley, L. L., Kreher, K., Pfeilsticker, K., Boesch, H., Toon, G., Goutail, F., and Pommereau, J.-P.: Validation of POAM III $\mathrm{NO}_{2}$ measurements, J. Geophys. Res., 107(D20), 4432, doi:10.1029/2001JD001520, 2002.

Randall, C. E., Rusch, D. W., Bevilacqua, R. M., Hoppel, K. W., Lumpe, J. D., Shettle, E., Thompson, E., Deaver, L., Zawodny, J., Kyrö, E., Johnson, B., Kelder, H., Dorokhov, V. M., KönigLanglo, G., and Gil, M.: Validation of POAM III ozone: Comparisons with ozonesonde and satellite data, J. Geophys. Res., 108(D12), 4367, doi:10.1029/2002JD002944, 2003.

Randall, C. E., Harvey, V. L., Singleton, C. S., Bailey, S. M., Bernath, P. F., Codrescu, M., Nakajima, H., and Russell III, J. M.: Energetic particle precipitation effects on the Southern Hemisphere stratosphere in 1992-2005, J. Geophys. Res., 112, D08308, doi:10.1029/2006JD007696, 2007.

Raspollini, P., Belotti, C., Burgess, A., Carli, B., Carlotti, M., Ceccherini, S., Dinelli, B. M., Dudhia, A., Flaud, J.-M., Funke, B., Höpfner, M., López-Puertas, M., Payne, V., Piccolo, C., Remedios, J. J., Ridolfi, M., and Spang, R.: MIPAS level 2 operational analysis, Atmos. Chem. Phys., 6, 5605-5630, 2006, http://www.atmos-chem-phys.net/6/5605/2006/.
Russell III, J. M., Gordley, L. L., Park, J. H., Drayson, S. R., Hesketh, D. H., Cicerone, R. J., Tuck, A. F., Frederick, J. E., Harries, J. E., and Crutzen, P. J.: The Halogen Occultation Experiment, J. Geophys. Res., 101, 10 777-10 797, 1993.

Sander, S. P., Friedl, R. R., Golden, D. M., Kurylo, M. J., Huie, R. E., Orkin, V. L., Moortgat, G. K., Ravishankara, A. R., Kolb, C. E., and Molina, M. J.: Chemical Kinetics and Photochemical Data for Use in Atmospheric Studies, Evaluation Number 14: update of key reactions, Tech. rep., Jet Propulsion Laboratory, California Institute of Technology, Pasadena, California, 2003.

Sandu, A., Daescu, D., and Carmichael, G.: Direct and Adjoint Sensitivity Analysis of Chemical Kinetic Systems with KPP: I - Theory and Software Tools, Atmos. Environ., 37, 5083-5096, 2003.

Solomon, S. and Brasseur, G.: Polar Ozone, in: The stratosphere and its role in the climate system, edited by: Brasseur, G. P., Springer-Verlag, 253-259, 1997.

Strahan, S. E. and Polansky, B. C.: Meteorological implementation issues in chemistry and transport models, Atmos. Chem. Phys., 6, 2895-2910, 2006, http://www.atmos-chem-phys.net/6/2895/2006/.

Talagrand, O. and Courtier, P.: Variational assimilation of meteorological observations with the adjoint vorticity equation, I, Theory, Q. J. Roy. Meteor. Soc., 23, 1311-1328, 1987.

Vigouroux, C., De Mazire, M., Errera, Q., Chabrillat, S., Mahieu, E., Duchatelet, P., Wood, S., Smale, D., Mikuteit, S., Blumenstock, T., Hase, F., and Jones, N.: Comparisons between groundbased FTIR and MIPAS N2O and HNO3 profiles before and after assimilation in BASCOE, Atmos. Chem. Phys., 7, 377-396, 2007, http://www.atmos-chem-phys.net/7/377/2007/.

Wargan, K., Stajner, I., Pawson, S., Rood, R. B., and Tan, W.-W.: Assimilation of ozone data from the Michelson Interferometer for Passive Atmospheric Sounding, Q. J. Roy. Meteor. Soc., 131, 2713-2734, 2005.

Wetzel, G., Bracher, A., Funke, B., Goutail, F., Hendrick, F., Lambert, J.-C., Mikuteit, S., Piccolo, C., Pirre, M., Bazureau, A., Belotti, C., Blumenstock, T., De Mazière, M., Fischer, H., Huret, N., Ionov, D., López-Puertas, M., Maucher, G., Oelhaf, H., Pommereau, J.-P., Ruhnke, R., Sinnhuber, M., Stiller, G., Van Roozendael, M., and Zhang, G.: Validation of MIPAS-ENVISAT $\mathrm{NO}_{2}$ operational data, Atmos. Chem. Phys., 7, 3261-3284, 2007, http://www.atmos-chem-phys.net/7/3261/2007/. 